\title{
Geología y procesos de remoción en masa asociados a un domo volcánico tipo couleé: cerro El Tenayo, Tlalnepantla, Estado de México
}

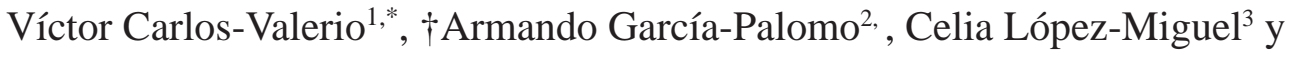 \\ Adriana H. Galván-García ${ }^{1}$ \\ ${ }^{1}$ Posgrado en Ciencias de la Tierra, Instituto de Geología, Universidad Nacional Autónoma de México. \\ ${ }^{2}$ Departamento de Geología Regional, Instituto de Geología, Universidad Nacional Autónoma de México. \\ ${ }^{3}$ Centro Regional de Investigaciones Multidisciplinarias, Universidad Nacional Autónoma de México. \\ *victorgeozienziaz@hotmail.com
}

\begin{abstract}
Resumen
El cerro El Tenayo está localizado al SW de la Sierra de Guadalupe. Se trata de un domo volcánico tipo tipo couleé o domo lava, emplazado sobre una paleotopografía que controló la dirección del flujo hacia el $\mathrm{S} 40^{\circ} \mathrm{W}$, coincidiendo con la orientación del eje mayor de la estructura. El domo es afectado por la falla Tenayuca y presenta en su superficie un arreglo sistemático de bloques de variada geometría: tabulares, columnares, cuñas, sub-redondeados o de forma irregular. Las discontinuidades que delimitan a los bloques son juntas de enfriamiento, planos de flujo y fracturas de origen tectónico, lo cual controla los procesos de remoción en las laderas. De acuerdo con la disposición de los bloques y la orientación de las discontinuidades con respecto al frente del talud, los mecanismos potenciales de movimiento son volteo, deslizamiento plano y en cuña así como flujos de detritos y caídas. Finalmente se realiza una zonificación del domo con fines descriptivos y se dan algunas recomendaciones generales a considerar en los trabajos de mitigación.
\end{abstract}

Palabras clave: Cerro El Tenayo, Falla Tenayuca, domo couleé, procesos de remoción en masa, discontinuidades.

\begin{abstract}
El Tenayo dome is located SW of the Guadalupe range (GR). The Tenayo is a coulee dome or lava dome, emplacement on a paleotopography that controls a flow direction of $S 40^{\circ} \mathrm{W}$, forming an elongated axe in that direction. The dome is affected by a reactivated fault named Tenayuca Fault. The Tenayo dome presents systematic arrangement of blocks with different geometry, as tabular, columnar, wedge, subrounded and irregular shapes. The discontinuities that bound the blocks are: cooling joints, flow bands and tectonic fractures. These features control the instability of the dome slopes. According to the blocks disposition and the orientation of the discontinuities, the main movements generated on the Tenayo hills are: toppling, planar and wedge slide, debris flow and rock fall formed by detachment and rolling.

In order to describe the landslides a zonation of the dome is proposed. Finally, some advices to consider in remedial works are given.
\end{abstract}

Key words: Cerro El Tenayo, Tenayuca Fault, couleé dome, landslides, discontinuities. 


\section{Introducción}

Los procesos de remoción en masa (PRM), de origen natural o inducido, representan un peligro que debe tenerse en cuenta en la planificación territorial. En el caso de regiones donde el relieve es de origen volcánico, los tipos de procesos estarán influenciados por el tipo de roca, la presencia de discontinuidades, ya sea estructuras primarias y secundarias, así como por la morfología de los cuerpos volcánicos. Un caso concreto lo representa la Cuenca de México (CM), la cual ha sido tema de investigación durante las últimas décadas (Mooser, 1975; Ramírez et al.,1983; De Cserna et al., 1988; Vázquez-Sánchez y Jaimes-Palomera, 1990; Mooser et al., 1992; Mooser et al., 1996; Tapia-Varela y López-Blanco, 2001) y en cuya porción suroccidental se ha desarrollado un gran núcleo poblacional, el cual está expuesto a la afectación de diversos peligros de origen geológico (García-Palomo et al., 2006a). Concretamente, cada año los PRM provocan pérdidas humanas y materiales en diversas zonas de la cuenca, lo que hace importante estudiar los factores que los originan para generar mapas de zonificación de peligros y proponer alternativas geotécnicas de mitigación. Una zona en particular, donde los PRM son variados y relativamente frecuentes, se presenta en la Sierra de Guadalupe (SG), en la porción central de la cuenca de México (Figura 1).

Diversos autores han estudiado los procesos de ladera en la Sierra de Guadalupe. Por ejemplo, Lugo-Hubp y Salinas-Montes (1996) realizaron un estudio de carácter geomorfológico en la Sierra de Guadalupe y generaron un mapa simplificado de zonas de inundación, de caída de rocas y de deslizamientos, Frausto (1999) estudió los procesos de remoción y la expansión lateral de suelo asociados a la sismicidad del graben de Cuautepec, el Servicio Geológico Metropolitano (2003) realizó un mapa cualitativo de peligros por deslizamientos usando la técnica de sobreposición de mapas temáticos, Carlos-Valerio (2003) realizó un inventario de bloques y un mapa simplificado de riesgo a partir del análisis de trayectorias de rocas en el domo El Tenayo, Espinoza-Hernández (2004) realizó una zonificación de peligros en la ladera sur del cerro del Chiquihuite, García-Palomo y colaboradores (2006b) publicaron un mapa con un inventario de PRM de la Sierra de Guadalupe, donde se resalta el control morfológico, estructural y antrópico de los procesos. Campos (2006) compara un método cualitativo con uno estadístico bivariado, para determinar el peligro por PRM en la SG y Concha (2006) hizo la caracterización geomecánica y modelación de los deslizamientos críticos.

Los PRM afectan directamente a la población e infraestructura civil, debido a que el acelerado crecimiento demográfico, aunado a la falta de planeación urbana, propició la ocupación de laderas potencialmente inestables. Este fenómeno ocupacional es notable en el domo volcánico "Cerro El Tenayo", al suroeste de la Sierra de Guadalupe (Figura 2), en el municipio de Tlalnepantla, donde la ur- banización comenzó de manera irregular en 1970 y para 1993, la población llegó a más de 100 m de altura a partir de la planicie lacustre (Figura 3a y 3b).

Mediante la obtención de mapas base (topográfico, de pendientes, modelo de relieve sombreado) y verificación de campo, se describen y caracterizan los PRM presentes en el domo El Tenayo. También se correlacionan los factores geológicos (litología y estructuras primarias como planos de flujo y enfriamiento) y estructurales (afectación tectónica, fracturamiento) con los tipos de PRM y su distribución. Finalmente se realiza una zonificación del domo en cuatro sectores y se plantean algunas recomendaciones generales para las alternativas geotécnicas de mitigación. Un plan de Protección Civil o un estudio detallado de estabilización de taludes, puede tomar como base este trabajo.

\section{Metodología}

Para el análisis geológico y estructural de la zona, se digitalizó un mapa topográfico con curvas de nivel a cada 10 m, escala 1: 10000 (Carta urbana E14A29-54, Tesorería del Distrito Federal); se generó en ILWIS (ver.3.0), un mo-

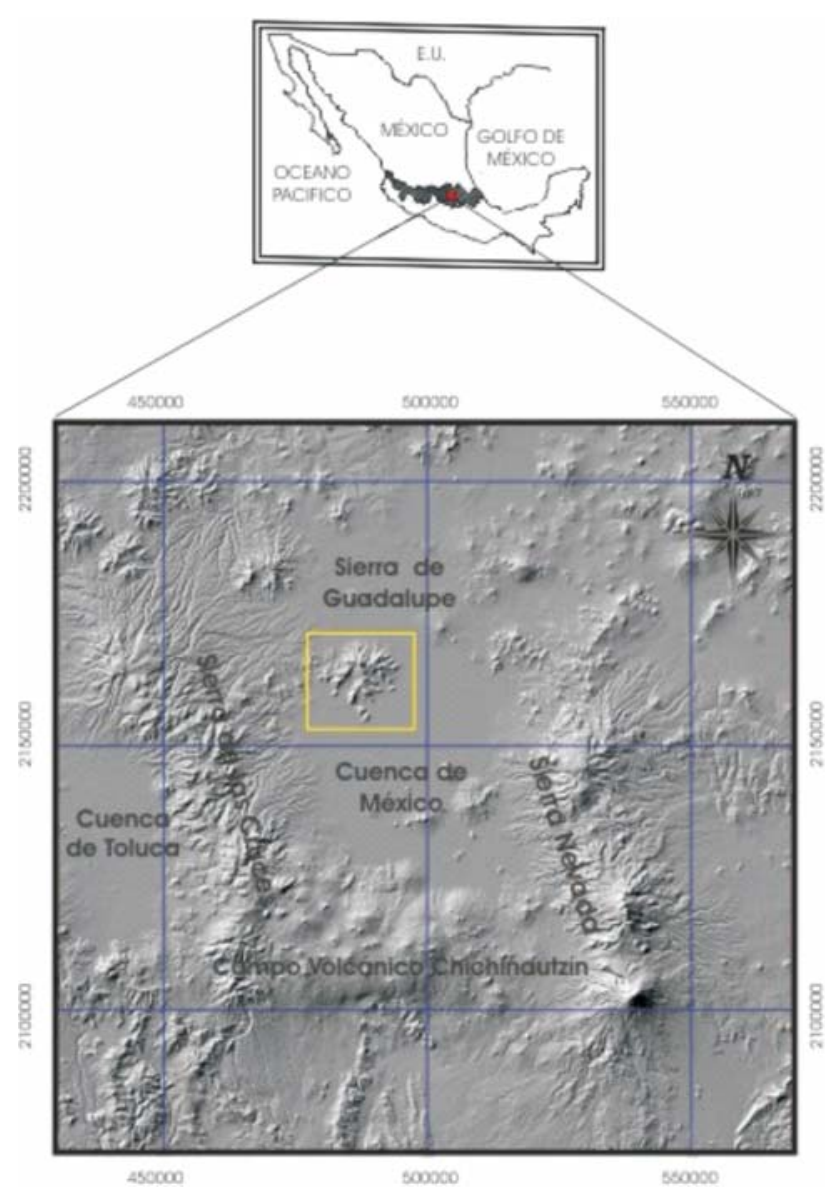

Figura 1. Localización de la Sierra de Guadalupe, en la porción central de la cuenca de México. 


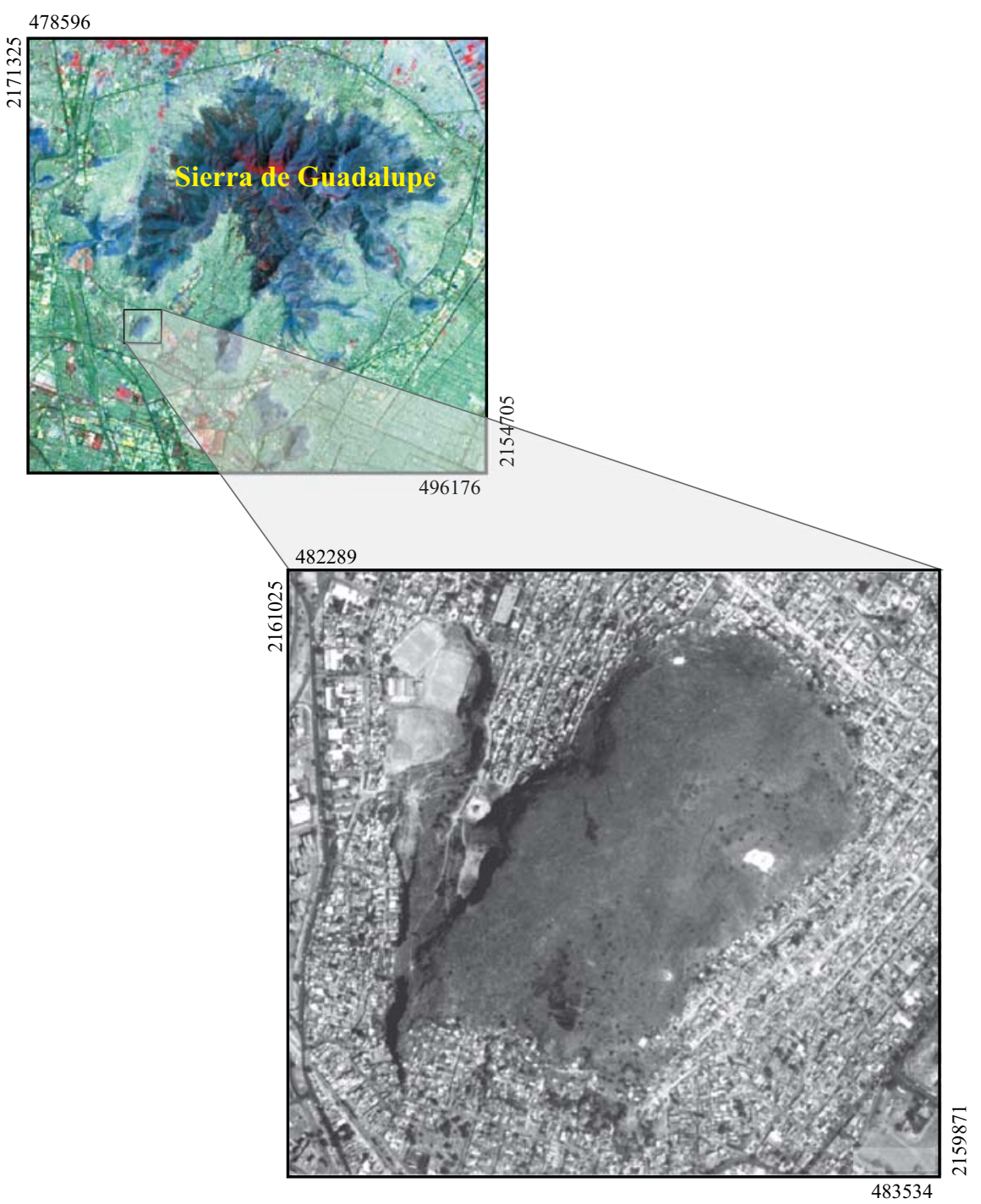

Figura 2. Localización del Domo El Tenayo, en el extremo SW de la Sierra de Guadalupe.

delo digital del terreno (MDT) y posteriormente el modelo de relieve sombreado y el mapa de pendientes (Figura 4). Con base en el análisis de fotos aéreas escala 1:4 500, en blanco y negro, se interpretaron lineamientos tales como fracturas, direcciones de flujo de lava, levees, escarpes de antiguos deslizamientos, la red de drenaje, así como cantiles y zonas de bloques. Para el trabajo de campo se diseñaron dos tipos de formatos (Figura 5): 1) de fracturamiento (International Society For Rock Mechanics, 1978; Hoek y Bray, 1996), con datos de las discontinuidades tales como orientación, espaciamiento, apertura, continuidad, relleno y rugosidad, así como coordenadas del afloramiento, área y tipo de muestreo, orientación del flujo y frecuencia de fracturamiento; 2) de bloques, con datos de forma, tamaño, coordenadas y mecanismo potencial de movimiento (Carlos-Valerio, 2003).

Para determinar las características del fracturamiento y su frecuencia, se utilizaron los métodos de la cuerda y del círculo (Van der Pluijm y Stephen, 2004). La frecuencia de fracturamiento, ya sea para cada familia de fracturas o para el sistema de fracturamiento general, se expresa como $f=F / L$ ó $f=F / A$, siendo $F$ el número de fracturas contadas dentro del rectángulo de ancho unitario y longitud L, o dentro del círculo de área A (Wheeler y Dixon, 1980; Priest, 1993). Los datos estructurales se representaron en la proyección de áreas iguales o de Schmidt, en el paquete SPHERISTAT (ver. 2.0). También se midieron datos de los planos de flujo para comprender el modo de emplazamiento del domo y su influencia en la generación de PRM. Los formatos diseñados para caracterizar bloques potencialmente inestables, contienen una foto así como sus características más importantes (localización, geometría, condiciones de apoyo y otras observaciones puntuales). En algunos casos, los mecanismos potenciales de movimiento de los bloques fueron establecidos a partir de los datos de orientación de las discontinuidades con respecto al frente del talud (prin- 

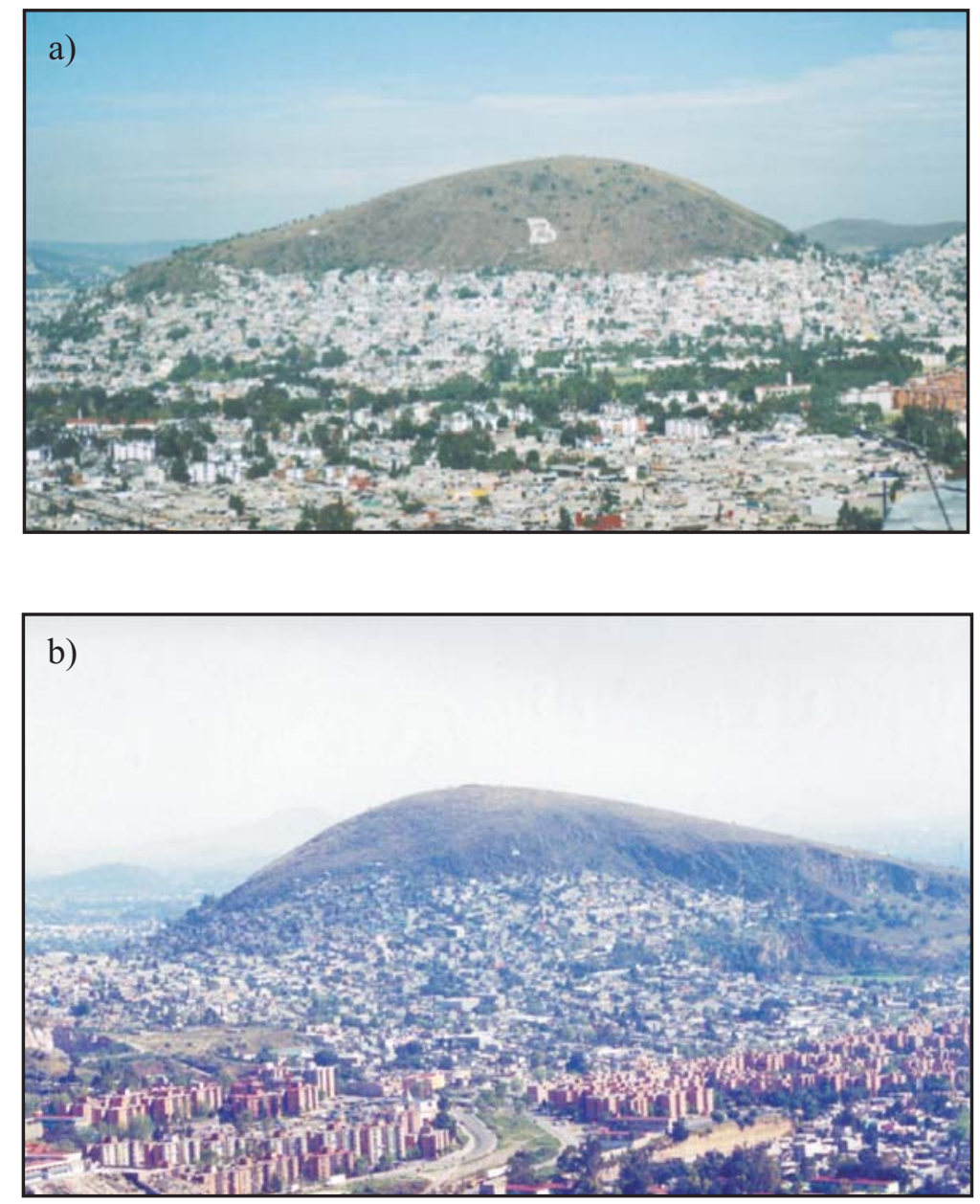

Figura 3. Vistas panorámicas del domo: a) vista SE y b) vista NW. Se aprecia el intenso crecimiento urbano alrededor y en los flancos del domo, donde existen abundantes zonas de potencial inestabilidad.

cipalmente volteo y deslizamiento), o bien se reconocieron visualmente (tal es el caso de la caída y el flujo de detritos). Finalmente, de acuerdo con la morfología y estructura del domo, se realizó una zonificación y se describieron los PRM característicos de cada sector.

\section{Marco geológico}

\subsection{Sierra de Guadalupe}

La Sierra de Guadalupe (SG) está constituida por estructuras volcánicas, tales como domos y estratovolcanes colapsados, los cuales tienen asociados depósitos de caída, flujos piroclásticos, flujos de lodo y avalanchas (Servicio Geológico Metropolitano, 2003). Los domos se llaman: El Tenayo, Chiquihuite, Cerro Gordo, El Tejocote, María Auxiliadora, Chalma y complejo dómico Tlayacampa, mientras que los estratovolcanes: Pico Tres Padres, Moctezuma, El Jaral, El Picacho y La Presa. Las rocas que constituyen a la Sierra de Guadalupe son pre- dominantemente, de composición dacítica y riolítica en el caso de los domos y andesítica, en el caso de los estratovolcanes (Servicio Geológico Metropolitano, 2003). La SG tiene un desnivel de $770 \mathrm{~m}$, entre las cotas 2240 a la 3 010, su relieve se originó a partir de procesos volcánicos y tectónicos, posteriormente fue modelado por la erosión y depositación. La disección se manifiesta por barrancos, circos de erosión y valles, algunos de ellos en forma de herradura; la red fluvial es de tipo dendrítico principalmente y está controlada por el intenso fracturamiento y fallamiento de la roca (Lugo-Hubp y Salinas-Montes, 1996). En lo que respecta a la edad, Mooser (1975) considera que este complejo volcánico tuvo su inicio en el Mioceno temprano. Lozano-Barraza (1968) reportó los fechamientos de dos rocas de la sierra, en Barrientos y en la fosa de Cuautepec, del orden de 14-15 millones de años, determinados por K-Ar y Jacobo-Albarrán (1985) reporta edades de entre 14 y $16 \mathrm{Ma}$, lo que permite determinar que el inicio de la SG se remonta al Mioceno Medio.

En la SG se reconocen principalmente tres sistemas de fallas. El primero presenta una orientación N-S que, de 


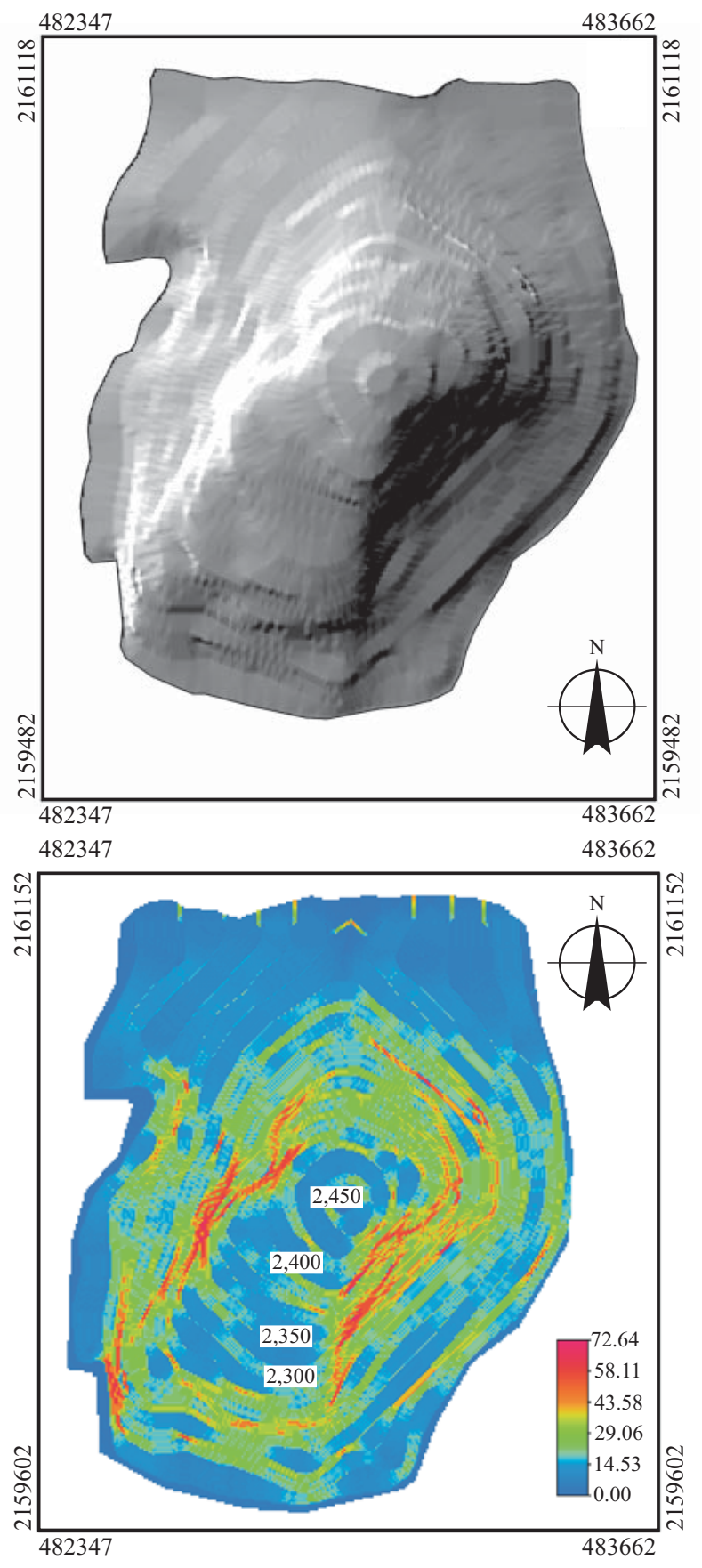

Figura 4. Modelo de relieve sombreado y mapa de pendientes del domo El tenayo. Las zonas que presentan mayor pendiente se concentran en en el frente y flancos del domo.

acuerdo con las relaciones estructurales y estratigráficas, se considera como el más antiguo. El segundo sistema de fallas presenta una orientación $\mathrm{N} 30^{\circ}-45^{\circ} \mathrm{E}$ (De Cserna et a.l, 1988; Mooser et al., 1992) siendo las más importantes las fallas de Tenayuca y Chiquihuite, que delimitan la Fosa de Cuautepec (Figura 6). El tercer sistema de fallas afecta a rocas jóvenes y tiene una orientación $\mathrm{E}-\mathrm{W}$; a este sistema de fallas pertenece la Fosa de Barrientos, delimitada por el Pilar de Chilpa al norte y por el Pilar de Tlayacampa al sur (Servicio Geológico Metropolitano, 2003; Flores-Moro, 2006). En los planos de falla de estos dos últimos sistemas, se observan indicadores cinemáticos tales como: estrías, brechamiento tectónico, harina de falla y estructuras sigmoidales (Servicio Geológico Metropolitano, 2003).

\section{2.- Cerro El Tenayo}

El cerro el Tenayo es un domo exógeno tipo coulee, ya que cerca del centro de emisión tiene una forma circular, típica de un domo, pero hacia la porción SW presenta las características de un flujo de lava. Fue alimentado por un dique orientado $\mathrm{N} 40^{\circ} \mathrm{E}$ y en fotografías áreas se identificaron las crestas de presión u ojivas, que muestran la dirección del flujo hacia el $\mathrm{S} 40^{\circ} \mathrm{W}$, la cual posiblemente estuvo controlada por una inclinación de la paleotopografía (Figura 7).

Visto en planta, el domo tiene una forma elíptica, con el eje mayor en sentido $\mathrm{N} 40^{\circ} \mathrm{E}$ y el eje menor en sentido $\mathrm{N} 50^{\circ} \mathrm{W}$; su altura con respecto a la planicie lacustre es de $250 \mathrm{~m}$. El drenaje es de tipo radial y está controlado por las discontinuidades. En la parte superior del domo la pendiente es suave, de 0 a $15^{\circ}$; hacia la porción $\mathrm{N}$ y $\mathrm{S}$ es moderada, de $15^{\circ}$ a $35^{\circ}$; mientras que en los flancos NW, SE y en el frente del derrame, la pendiente es mayor a $45^{\circ}$, alcanzando en algunas zonas $90^{\circ}$ (Figura 4).

Geológicamente, el domo está conformado por una sucesión de derrames de lava de composición dacítica, con unidades de flujo bandeadas y espesores que varían de algunos centímetros hasta 2 metros de espesor. Está rodeado por depósitos de talud y por abanicos de material aluvial y piroclástico asociados a la sierra de Guadalupe. A partir de la fotointerpretación y de mediciones de los planos de flujo, se definió la zona alimentadora en la parte más alta del domo, donde existe fracturamiento vertical y las direcciones de flujo medidas muestran una geometría concéntrica y echados variables (Figura 8). Hacia la parte SW del domo, que es la dirección del movimiento del flujo, los echados varían debido a la dinámica del emplazamiento; en esta región se desarrollan fracturas de geometría lístrica, esto es verticales hacia arriba y subhorizontales hacia abajo, las cuales pueden estar relacionadas con estructuras de rampa. En la porción W y SW, existen cantiles de minas a cielo abierto antiguamente explotadas donde se reconocieron bandas de flujo con orientación de minerales y xenolitos así como superficies de cizallamiento, lo cual permitió reconocer parte de la estructura interna del domo (Figura 9) y corroborar la dinámica del emplazamiento.

Respecto a la falla Tenayuca, ésta abarca una longitud de $7 \mathrm{~km}$ aproximadamente y se reconoce desde el cerro María Auxiliadora, al norte de la Sierra de Guadalupe, hasta su extremo SW, en el cerro Chalma de Guadalupe, donde se releva hacia el cerro El Tenayo; es de tipo normal, con una orientación de $\mathrm{N} 35^{\circ}-40^{\circ} \mathrm{E}$ y un fuerte buzamiento hacia el SE (De Cserna et al., 1988). Sobre los planos de falla se identificaron estrías verticales, escalones incongruentes, harina y brecha de falla (Figura 10a) así como 

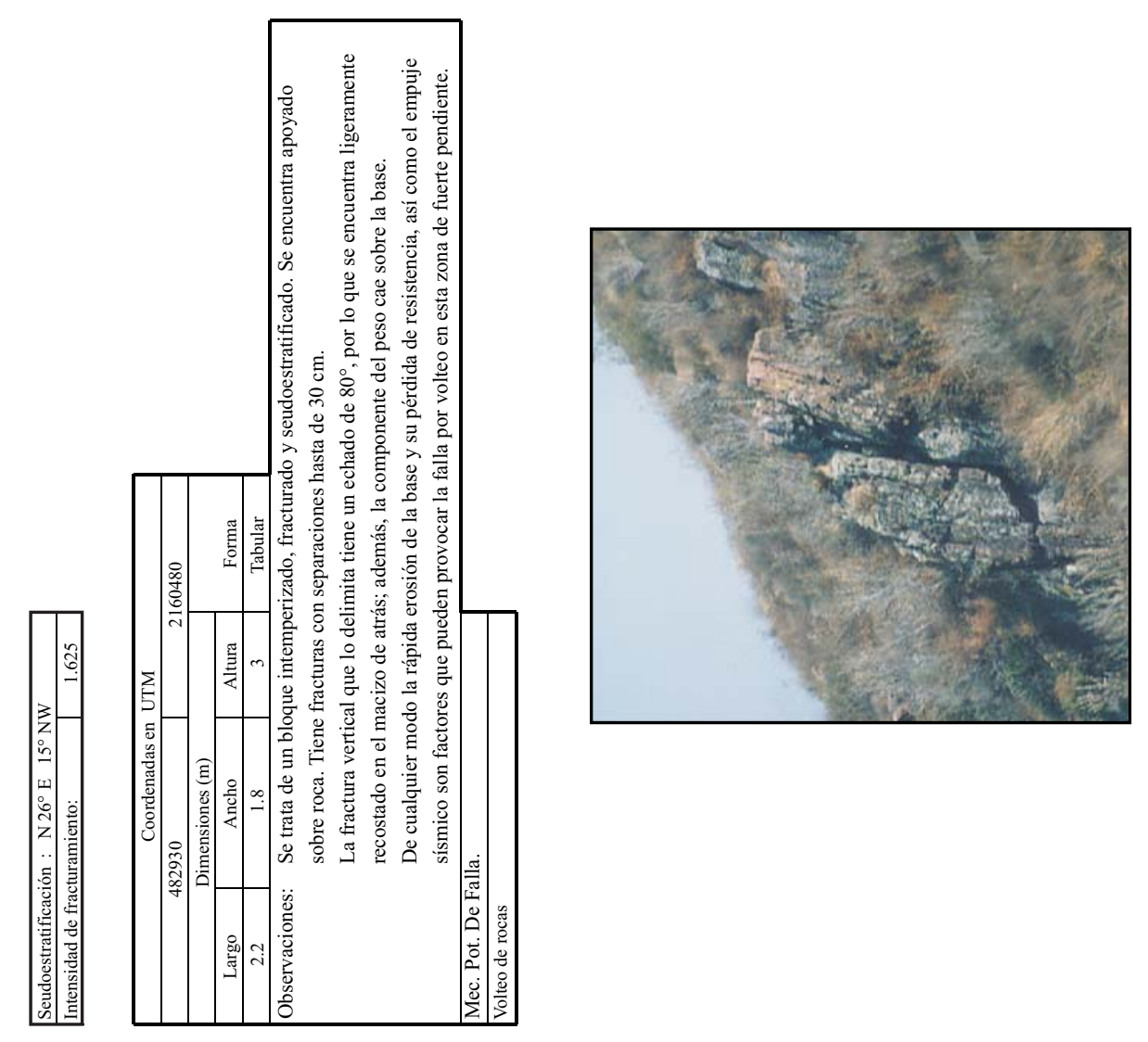

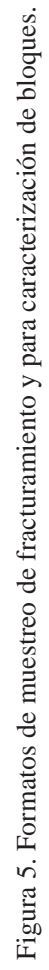
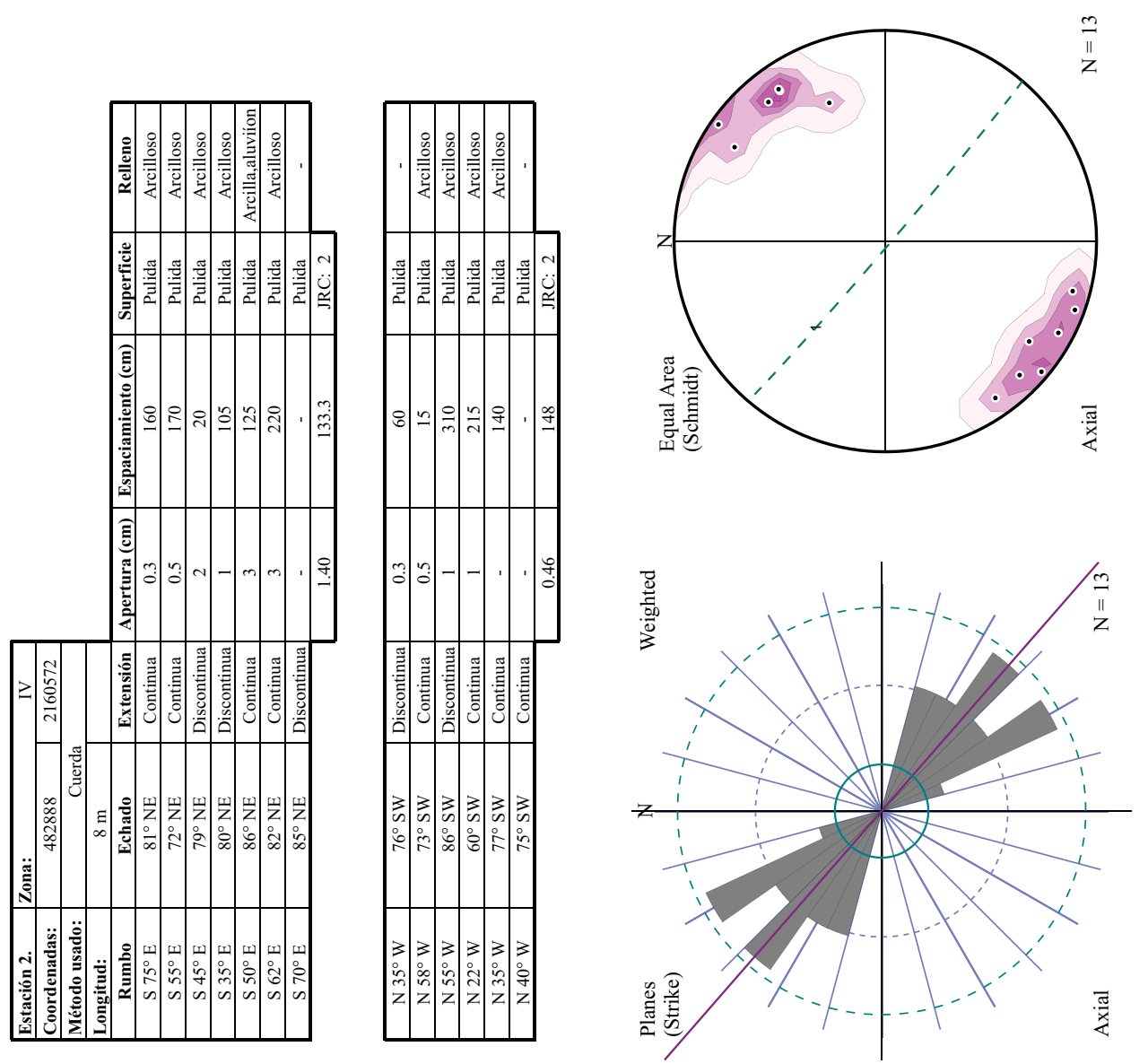


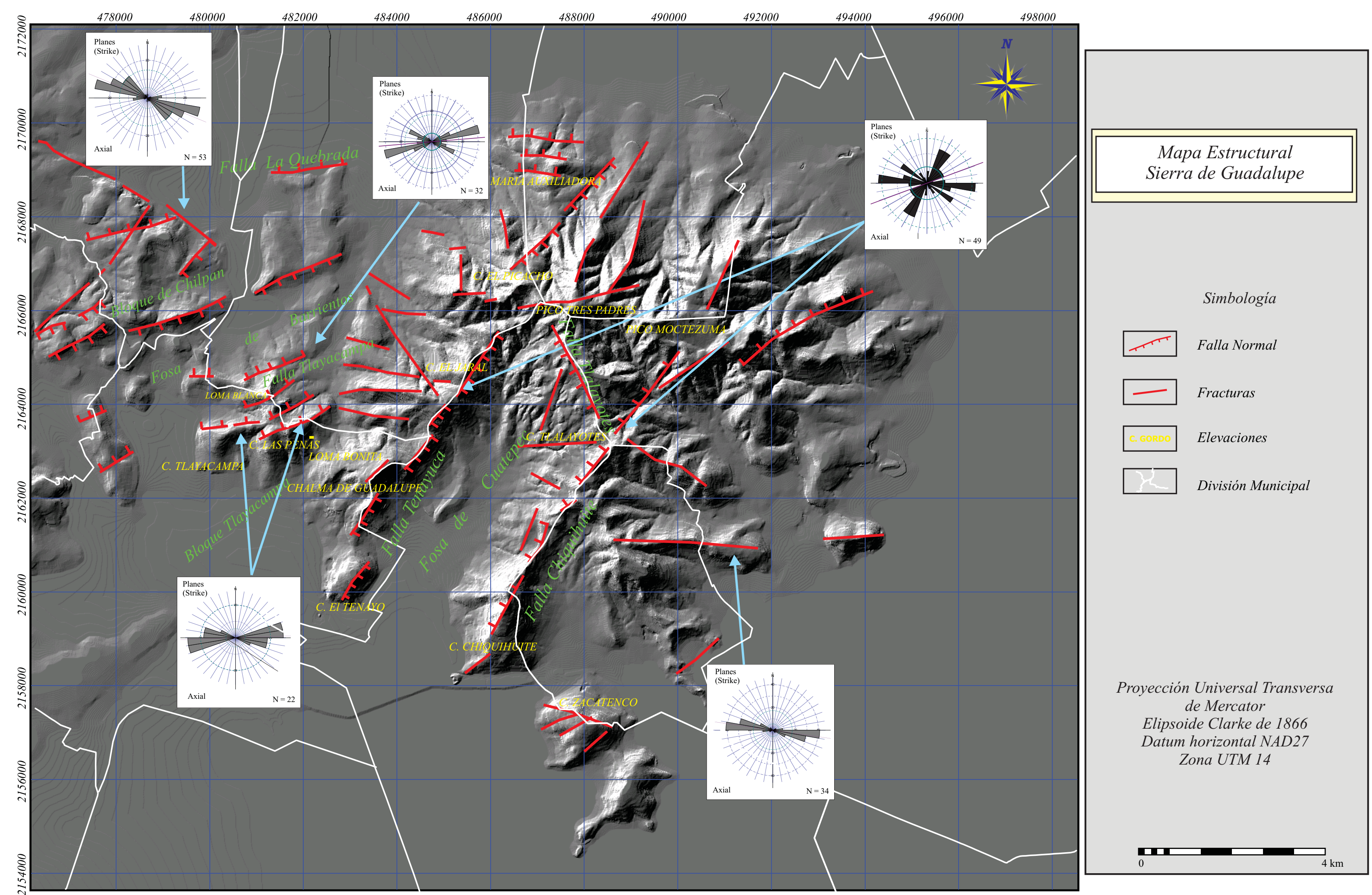




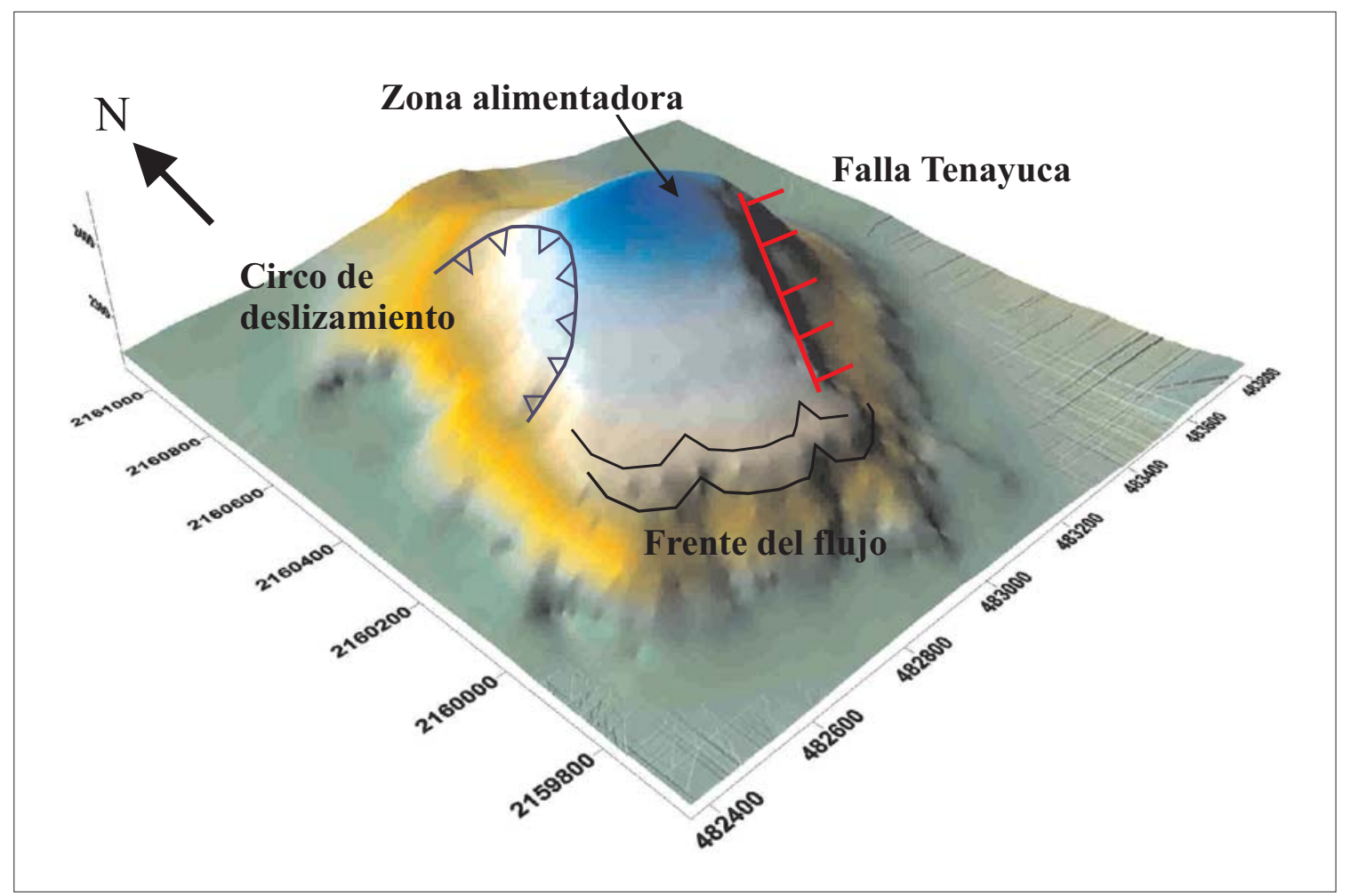

Figura 7. Modelo tridimensional del domo. Se muestran el frente del flujo, hacia el SW y la falla Tenayuca, en la porción SE.

estructuras sigmoidales (Figura 10b) que indican un sentido de movimiento normal. La expresión estructural de esta falla es evidente en el flanco E del domo donde hay una zona de $60 \mathrm{~m}$ de ancho aproximadamente, con abundante fracturamiento. La cinemática de esta falla ocasionó un basculamiento del domo hacia el NW, prueba de ello es que presenta estructuras en forma de herradura abierta que indican la ocurrencia de colapsos gravitacionales en el pasado, como se puede inferir por la existencia de circos de deslizamiento (Figura 7), superficies pulidas de falla, intenso fracturamiento y bloques basculados. La influencia antrópica en el domo se manifiesta principalmente por cortes a la ladera, ya sea para urbanización o explotación del material rocoso para su utilización en mampostería, o bien mediante la vibración de vehículos pesados, filtraciones de agua de uso doméstico, sobrecarga de viviendas (que en algunos casos llegan a ser de tres o cuatro niveles) y la quema de vegetación.

\section{4.- Resultados}

\subsection{Zonificación}

Con base en la fotointerpretación, los recorridos de campo y las características morfológicas y estructurales del domo, se delimitaron cuatro zonas (Figura 11) que presentan rasgos característicos en función del fracturamiento y desarrollo de bloques en la superficie. Esta zonificación, cumple básicamente con fines descriptivos y para separar de manera cualitativa aquellos sectores que se consideran críticos de presentar determinados tipos de PRM.

La terminología utilizada para describir los procesos es la descrita por Hutchinson (1988) para materiales rocosos, que consiste en volteo, deslizamiento plano y en cuña, caída por desprendimiento (proceso primario), caída por rodamiento (proceso secundario) y flujo de detritos.

A continuación se describen los rasgos principales de cada zona y los PRM que las caracterizan (Fig $11 \mathrm{y}$ Figura 12):

\section{Zona I}

Corresponde a la parte frontal del derrame, en la porción SW del domo, presenta la mayor concentración de levees y zonas de compresión debido al emplazamiento sucesivo de los derrames de lava. En el frente los planos de flujo tienden a la vertical, en lo que se conoce como estructura de rampa (Francis y Oppenheimer, 2004), siendo posible el volteo de rocas. Asimismo, en los frentes de flujo de lava se generan bloques en posición de cantiliver, es decir sobresaliendo del talud sin un apoyo en la base, que pueden presentar desprendimiento (Figura 13a). También hay brechas de enfriamiento expuestas a la disgregación mecánica debido al intemperismo, a los efectos del agua y de raíces.

Existe un corte vertical en la ladera, localizado al W de esta zona I, realizado antiguamente para la extracción 


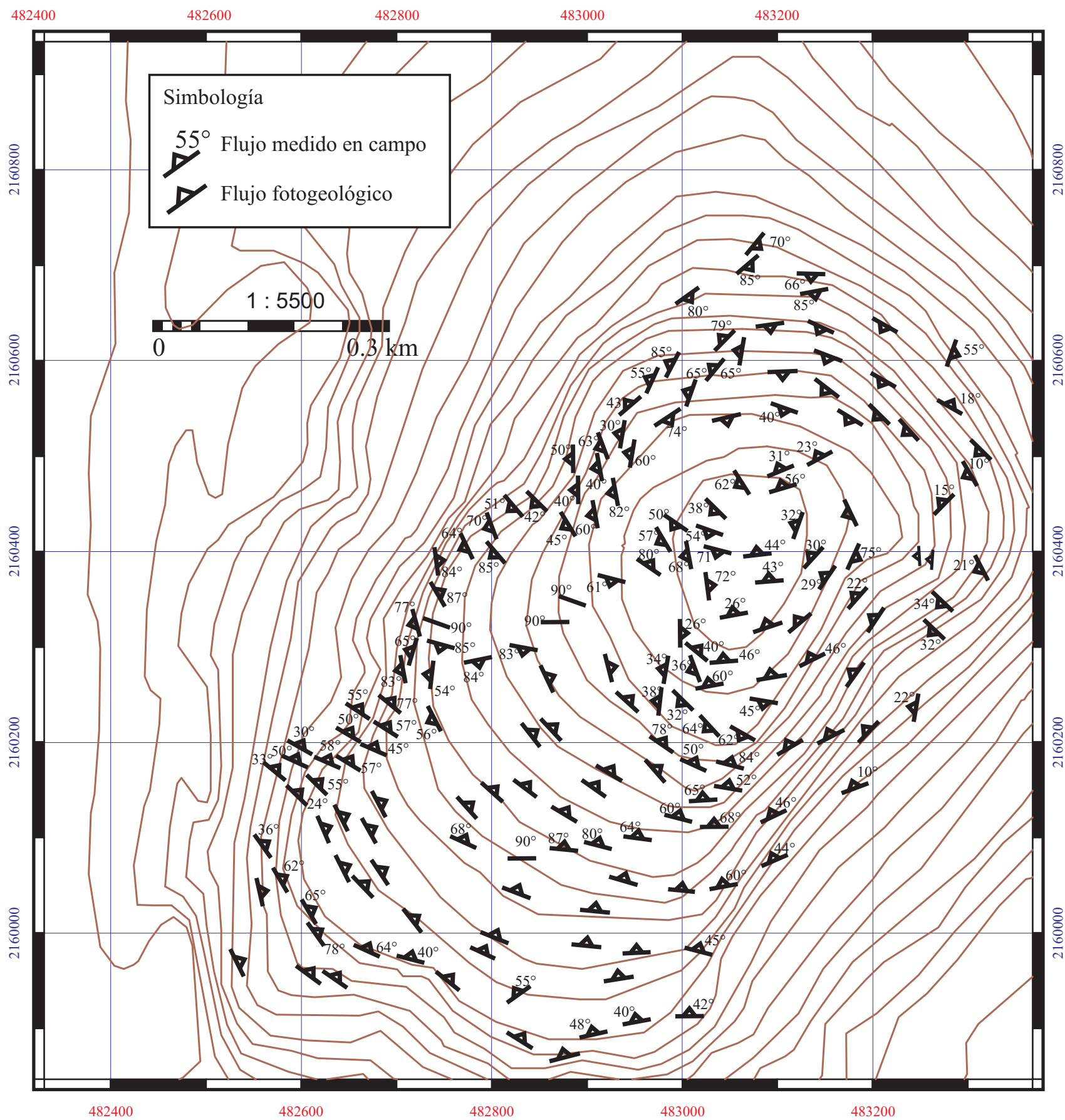

Figura 8. Mapa de planos de flujo con valores de orientación (rumbo y echado), medidos y obtenidos de la fotointerpretación, que ayudan a comprender la forma de emplazamiento del domo.

del material rocoso, para su utilización en la construcción. En estos taludes se forman bloques que pueden presentar deslizamiento y desprendimiento (Figura 13b) así como volteo (Figura 13c).

\section{Zona II}

Comprende la parte SE del domo y es caracterizada por levees y un intenso fracturamiento, del orden de 5 a 7 fracturas por metro lineal. La expresión estructural de la falla Tenayuca es clara en esta zona, se caracteriza por una franja de 50-60 m de espesor, donde existe abundante fracturamiento, con espaciamientos que van del orden de centímetros a decenas de centímetros. Las fracturas tienen una apertura de 0,3 a $5 \mathrm{~cm}$, presentan relleno arcilloso y tienen baja rugosidad. Los bloques presentes en esta zona son de forma tabular, columnar, irregular y sub-redondeada, de tamaños variables, de 0,5 hasta 5 m (Figura 14 a). Los bloques tabulares están asociados al volteo (Figura 14b) 


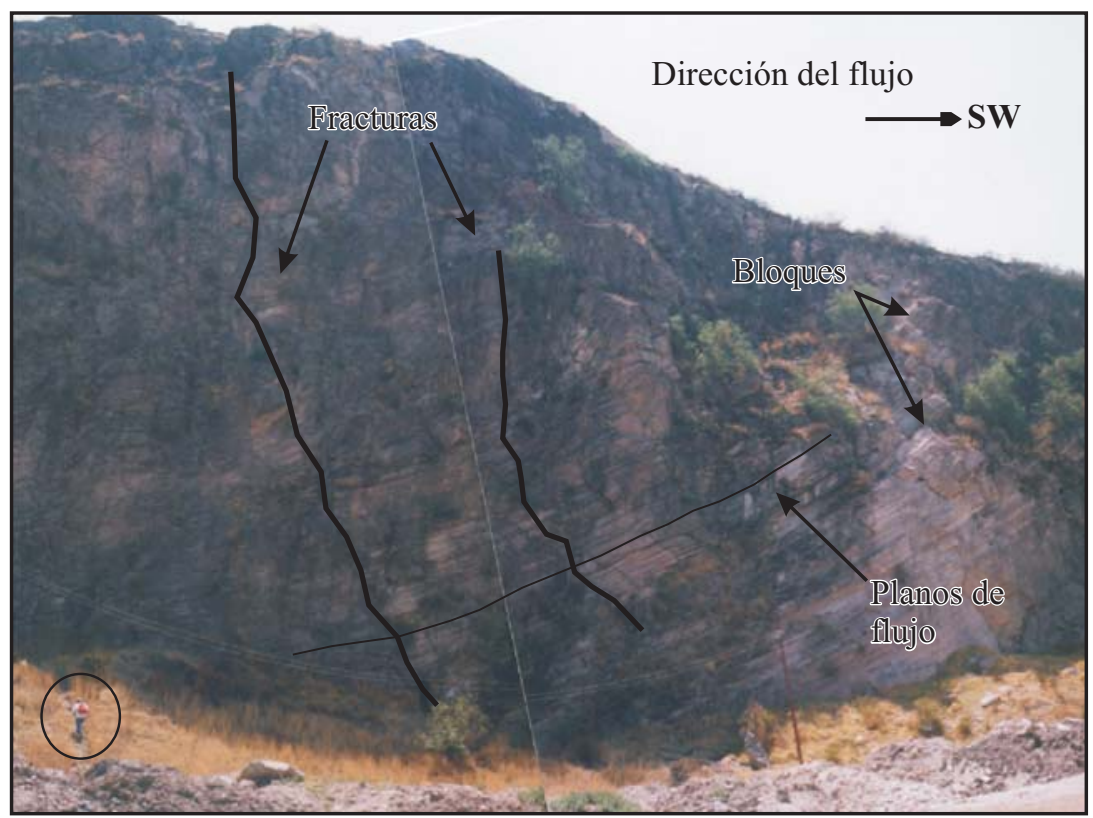

Figura 9. Parte de la estructura interna que se puede reconocer en un corte vertical, en la porción SW del domo, donde se aprecia el bandeamiento de los planos de flujo y fracturas asociadas al emplazamiento. El círculo señala una persona como escala.

y deslizamiento, mientras que existen bloques subredondeados apoyados sobre la ladera con posibilidad de rodar (Figura 14c). Se observaron bloques tabulares o columnares cuyo mecanismo de movimiento es combinado, con volteo y deslizamiento traslacional (Figura 15). Por efecto de la falla, en esta zona se generó un circo de erosión, que funciona como ladera de captación (Figura 16a), donde hay material detrítico, con pendientes de $30^{\circ}$ o mayores por lo que puede formarse un flujo de detritos en caso de una precipitación abundante. También hay bloques tabulares
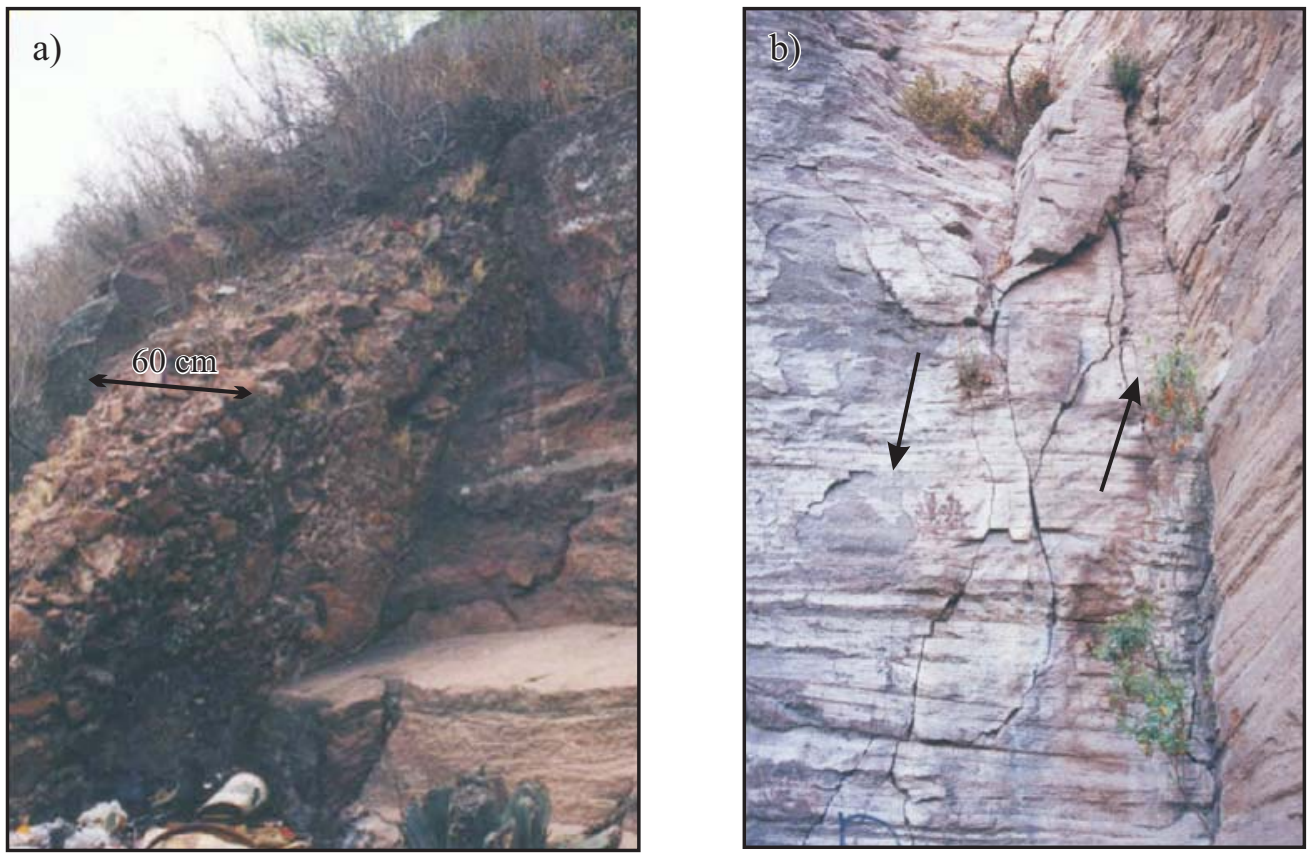

Figura 10. a) Brecha de falla, fuertemente consolidada, con un espesor promedio de $60 \mathrm{~cm}$; b) sigmoides de deformación que muestran la dirección del fallamiento. 


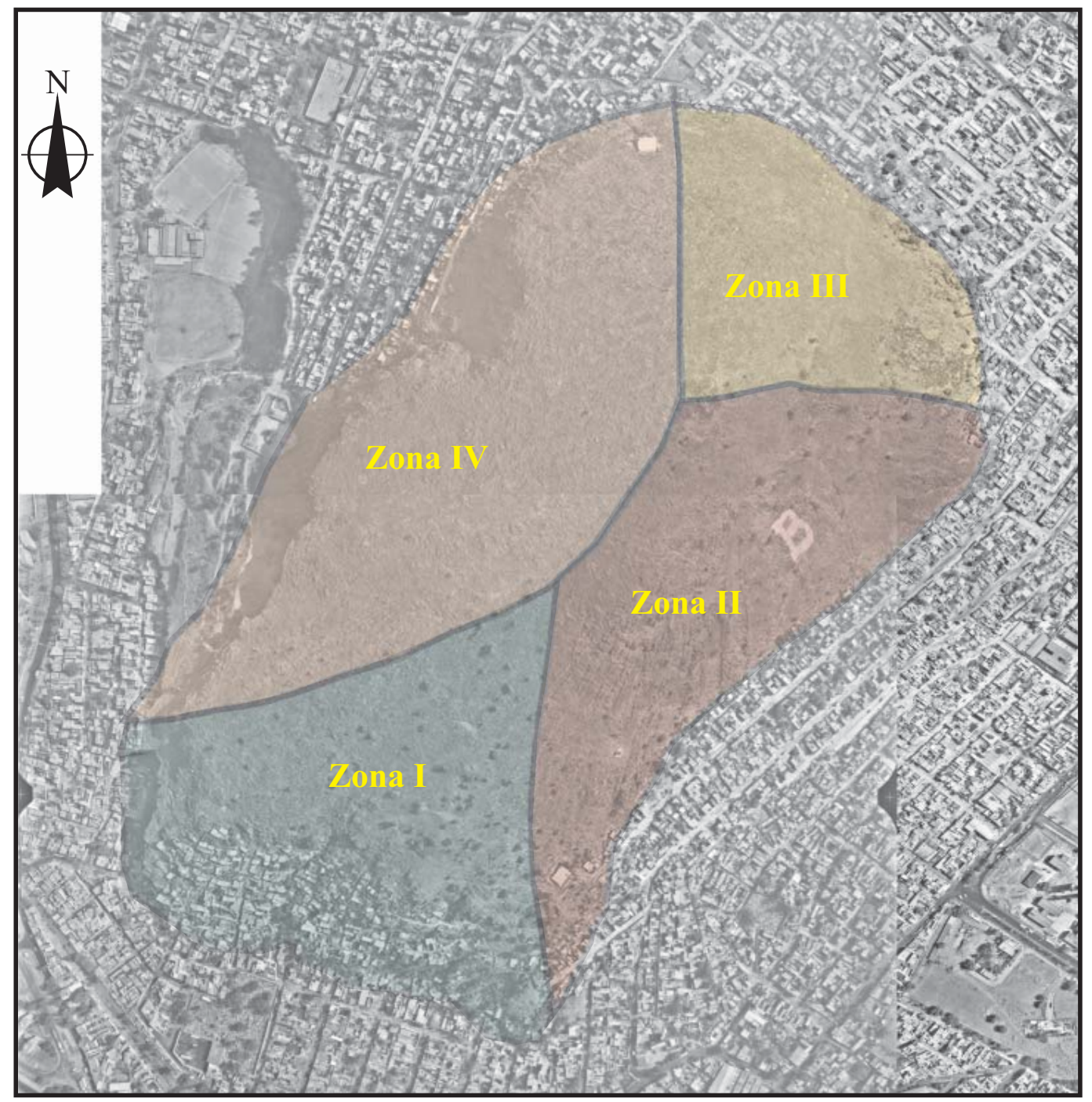

Figura 11. Zonificación general del domo El Tenayo. La zona I corresponde con el frente del derrame (SW), las zonas II y IV con los flancos SE y NW respectivamente y la zona III con la parte trasera del domo (NE).

y cúbicos de hasta 2 m en su dimensión mayor, apoyados unos sobre otros (Figura 16b) con el potencial de presentar alguna inestabilidad.

\section{Zona III}

Esta zona corresponde a la parte NE del domo, donde se reconocieron pocos rasgos de fracturamiento. Existen algunos bloques sueltos, con tamaños de 1-2 $\mathrm{m}$ en su dimensión mayor (Figura 17a), que podrían rodar en caso de que se erosione la base, pero la pendiente en general es moderada $\left(0-30^{\circ}\right)$ aunque hay sectores localizados con pendientes mayores a $45^{\circ}$. En esta zona se conforman de manera natural algunas terrazas y hay abundante vegetación herbácea lo que impide que los bloques rueden con facilidad. El principal tipo de proceso es la caída por rodamiento, debido a la erosión e intemperismo, que redondea bloques originalmente tabulares (Figura 17b). Es la parte del domo que presenta menor número de afloramientos rocosos potencialmente inestables.

Zona IV

Esta zona comprende la parte NW del domo y se reconocieron rasgos de fracturamiento, algunos levees y un circo de deslizamiento, el cual sirve como ladera de captación que arrastra material detrítico y bloques de varios metros cúbicos (Figura 18a). Hay escarpes y cantiles con fracturamiento vertical, siendo común el volteo de rocas (Figura18b). Existen bloques, ya sea aislados o en grupos,

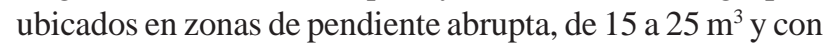
forma tabular, cúbica o redondeada, los cuales podrían rodar o deslizar en caso de que su base sea erosionada (Figura 19a y Figura 19b). Hay bloques de roca en cantiliver, delimitados por fracturas y cuyo mecanismo es el deslizamiento y desprendimiento. En algunos puntos la intersección de las discontinuidades no es ortogonal y esta variación puede dar lugar a cuñas o bloques de geometría irregular cuyo mecanismo principal es por deslizamiento, el cual puede 

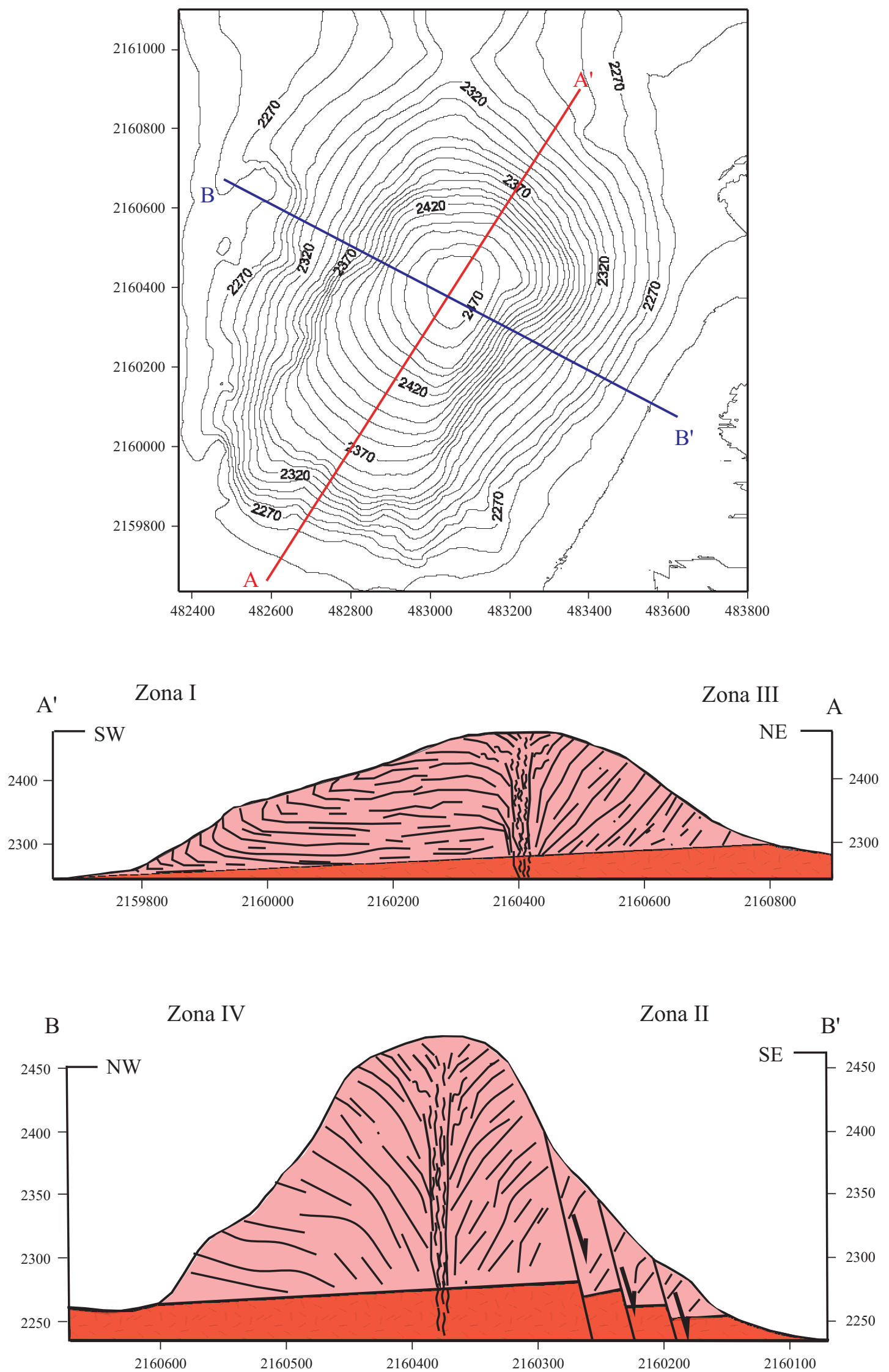

Figura 12. Secciones del domo, que muestran los rasgos de la falla, del frente del flujo y del basculamiento. 

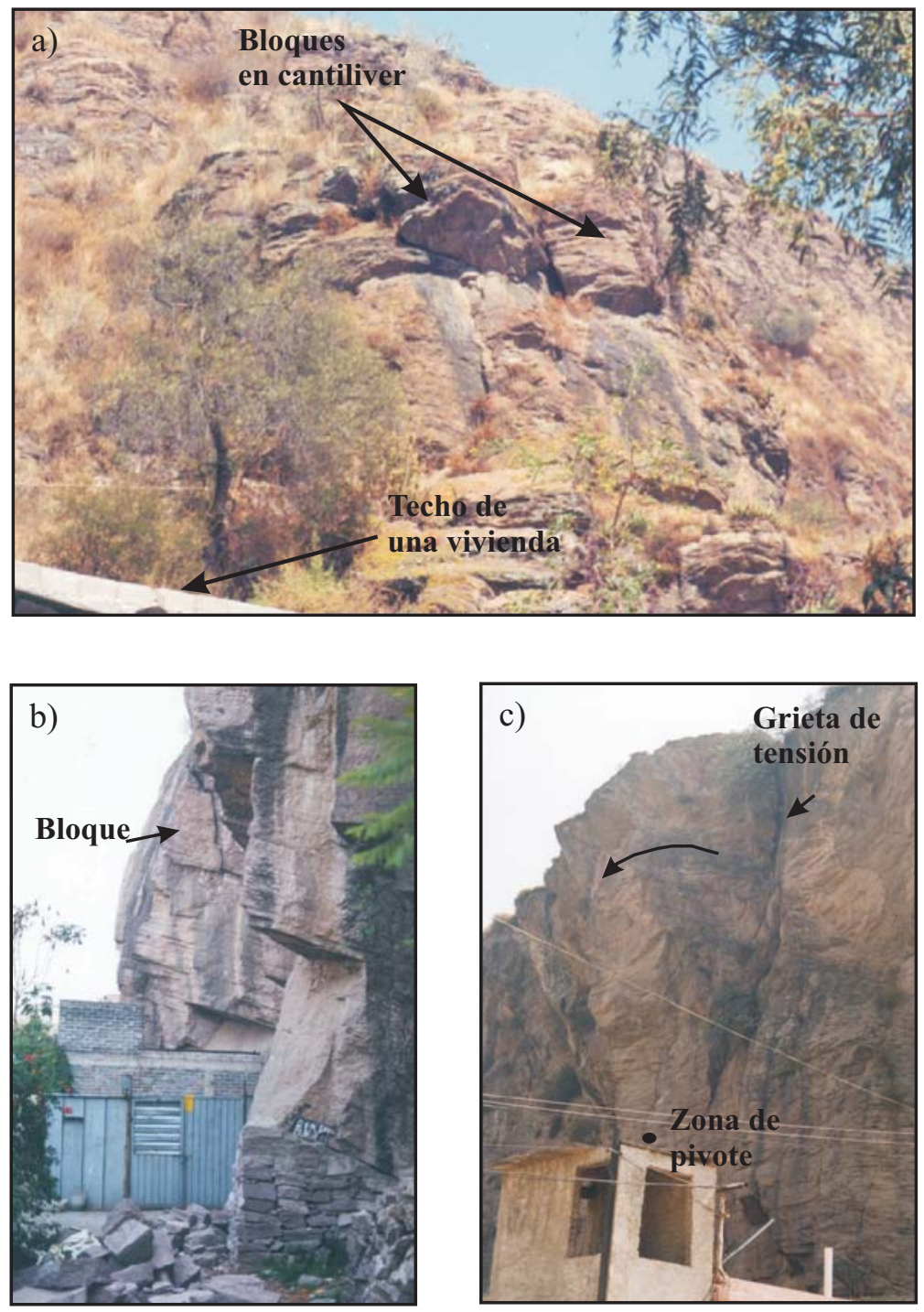

Figura 13. a) Bloques en cantiliver localizados justo arriba de la zona de viviendas. b) Potencial desprendimiento de bloques. c) Volteo de un bloque con forma de prisma, se aprecian las grietas de tensión en la cabecera del bloque.

ser plano, en cuña o en una superficie compuesta.

\section{Discusión}

Es importante conocer el tipo de roca y la estructura geológica de las laderas, pues dependiendo de su origen y formación, éstas heredarán rasgos estructurales y litológicos que influirán en la generación de PRM (Hutchinson, 1988; Capra et. al. 2003; Margielewski, 2006). Los taludes rocosos, generalmente se presentan como macizos afectados por discontinuidades y constituidos por bloques de diferentes dimensiones y formas que definen su estructura interna (Gaziev, 1984) lo que controla los tipos de procesos de remoción que pueden presentarse.

En el caso del domo El Tenayo, su modo de emplazamiento (a través de derrames sucesivos de lava) y la afectación por la falla Tenayuca, conforman la estructura de su superficie como un arreglo sistemático de bloques, de tamaño y geometría variada, lo que controla la distribución y tipos de PRM presentes. Las familias de discontinuidades que afectan al domo y definen la estructura interna y de la superficie son básicamente tres: planos de flujo, juntas de enfriamiento y fracturas de origen tectónico. Los planos de flujo se forman como respuesta a la fricción generada entre las paredes del conducto durante el ascenso del magma y se deforman en respuesta a los cambios de velocidad durante el avance del flujo, entre otras razones; las juntas de enfriamiento, se forman como respuesta al cambio en el estado de esfuerzos debido a variaciones de temperatura durante el flujo (Fink y Anderson, 2000) y las fracturas son inherentes al proceso de fallamiento normal (Figura 20).

Estas familias de discontinuidades se intersecan, ya sea ortogonalmente o de manera oblicua, definendo así la estructura de la superficie del domo como arreglos sistemáticos de bloques, los cuales generalmente están 

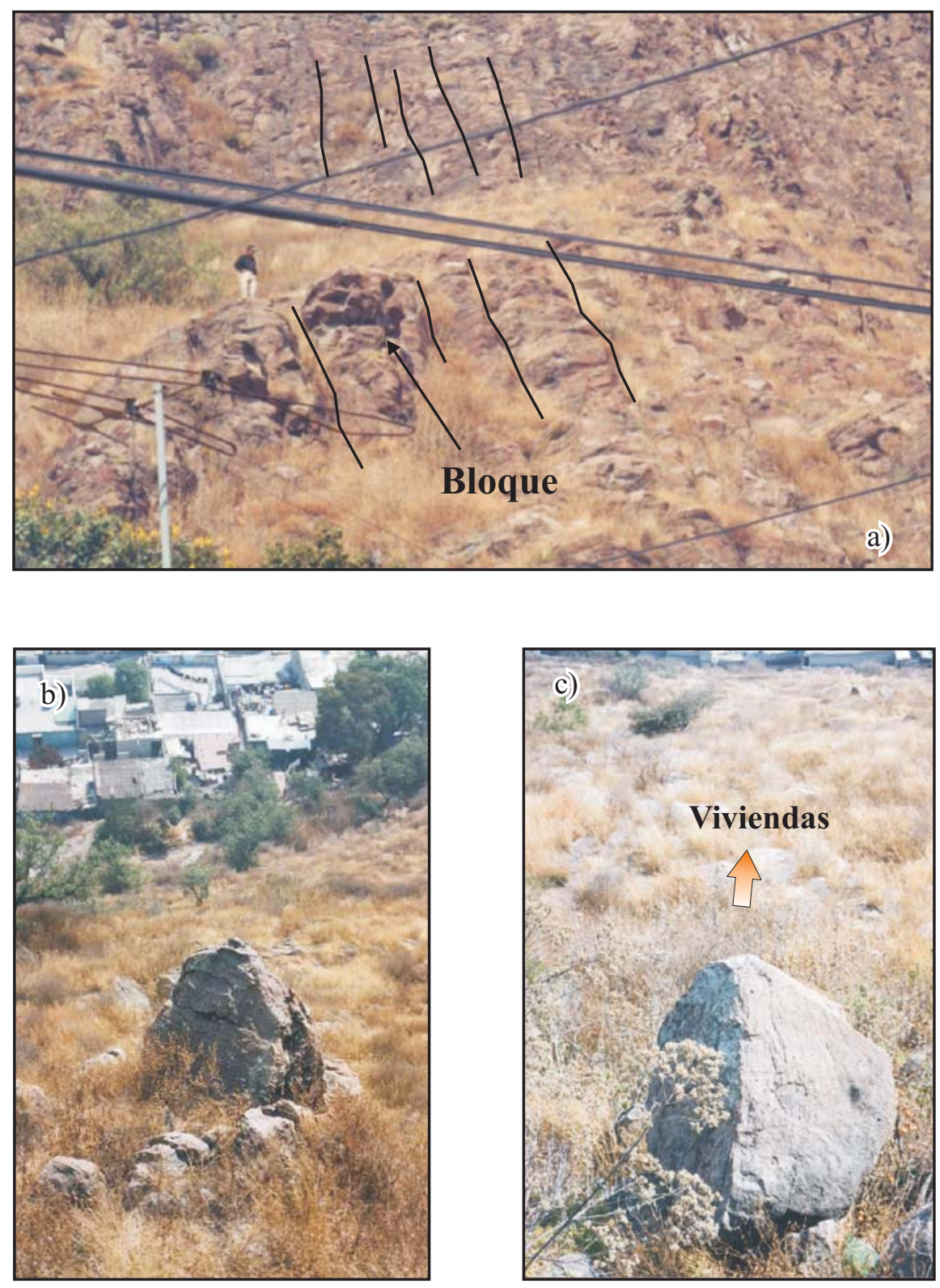

Figura 14. a) Aspecto del fracturamiento y de los bloques que se forman. Junto al bloque señalado se encuentra una persona como escala. b) Bloque tabular, que podría presentar el volteo hacia el frente y protectarse hacia el área de viviendas, las cuales presentan techos de lámina lo que incrementa su vulnerabilidad. c) Bloque redondeado en zona de fuerte pendiente, con el potencial de caer por rodamiento.

intemperizados, presentan tamaños que varían de unos cuantos centímetros hasta $6 \mathrm{~m}$ en la longitud mayor y son de forma tabular, columnar y en menor medida irregular y redondeada.

Los tipos de procesos de remoción en masa que se pueden presentar en el domo se resumen a continuación:

1) Caída por rodamiento, de bloques redondeados, subredondeados o irregulares. Este mecanismo se localiza en las zonas II y IV principalmente aunque también en la zona III. Está relacionado con bloques que han sido separados del macizo rocoso y que están simplemente apoyados en la ladera. El movimiento se puede originar básicamente por erosión y pérdida de apoyo en la base de los bloques y por fuerzas sísmicas.

2) Caída por desprendimiento, de bloques cúbicos o irregulares que están en cantiliver en zonas de pendiente abrupta. Este mecanismo es característico de la zona I y de una porción de la zona IV, donde hay escarpes y cantiles de origen antrópico que presentan bloques acuñados y/o delimitados por planos de debilidad. La disminución de la resistencia en las discontinuidades por los efectos del intemperismo y de raíces es uno de los principales detonantes.

3) Volteo de bloques tabulares o columnares, asociados a zonas de fuerte pendiente como escarpes de falla, cabeceras de circos de deslizamiento y frentes de flujo de 


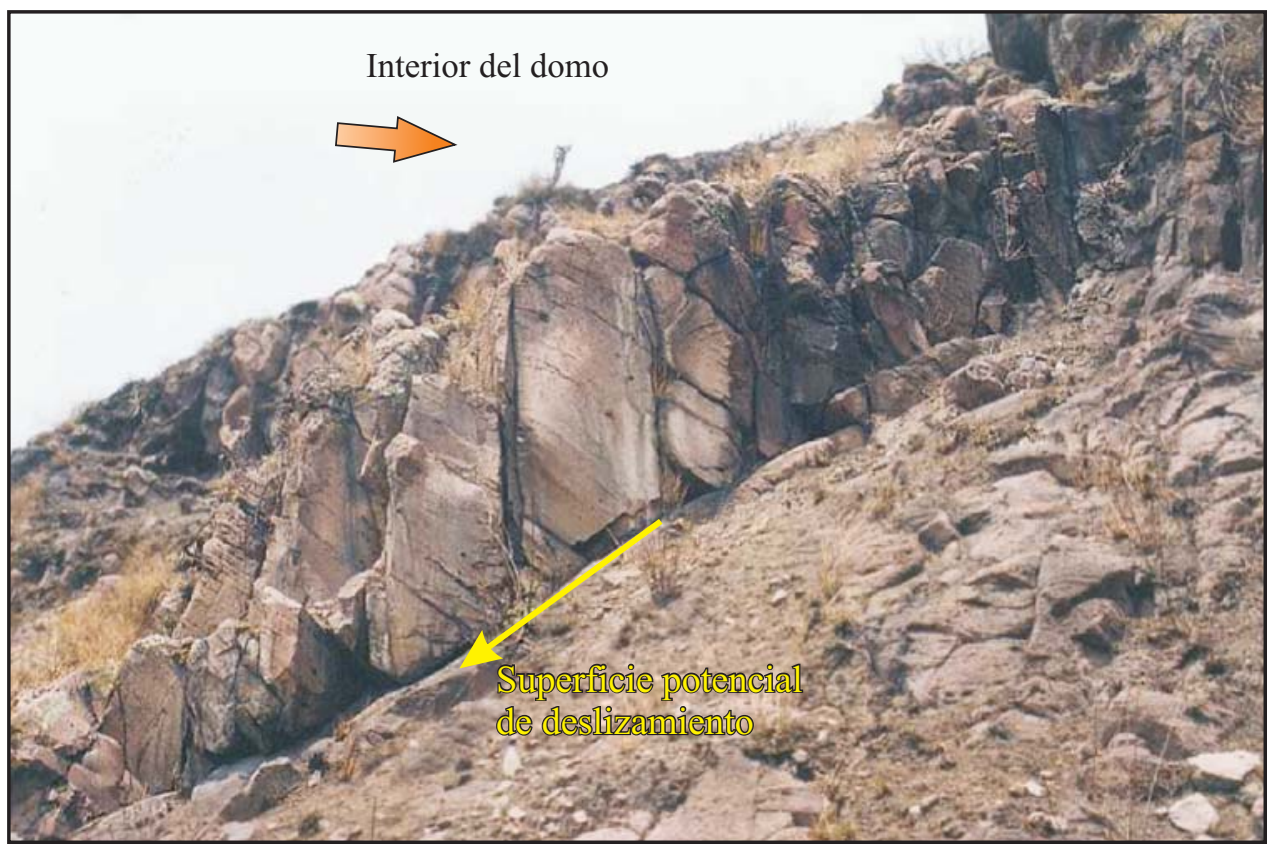

Figura 15. Bloques tabulares apoyados sobre un plano inclinado, donde se puede presentar el volteo y/o deslizamiento.

lava. Este mecanismo es característico de las zonas II y IV, donde existe fracturamiento vertical asociado y bloques tabulares o columnares definidos por la ortogonalidad de las discontinuidades. También se presenta en la zona I, donde puede existir volteo con flexión de estratos debido a la estructura de rampa formada por planos de flujo verticales. Entre los factores que afectan la estabilidad tenemos los empujes sísmicos y del agua, así como la sobrecarga de las construcciones (principalmente en la zona I).

4) Deslizamiento de bloques. Este mecanismo es común en las zonas II y IV y está asociado a bloques o cuñas cuyos planos o líneas de intersección afloran en la cara del talud, siendo posible su movimiento. También se origina en bloques tabulares que están apoyados sobre cobertura de suelo en zonas de fuerte pendiente. La pérdida progresiva de resistencia al esfuerzo cortante, la erosión de la base de los bloques y los afectos del agua y los sismos son los principales detonadores de este movimiento.

5) Flujos de material detrítico y bloques, que pueden formarse durante una precipitación intensa. Este proceso se presenta principalmente en la zona II y en menor medida en la IV, donde hay cabeceras que conforman laderas de captación y canalizan material detrítico y bloques hacia las partes más bajas. Estas zonas se caracterizan por un intenso fracturamiento y pendientes mayores a $30^{\circ}$.

Cualitativamente, se puede considerar a la zona II como la más crítica, debido a las fuertes pendientes, al intenso fracturamiento, el alto número de bloques sueltos
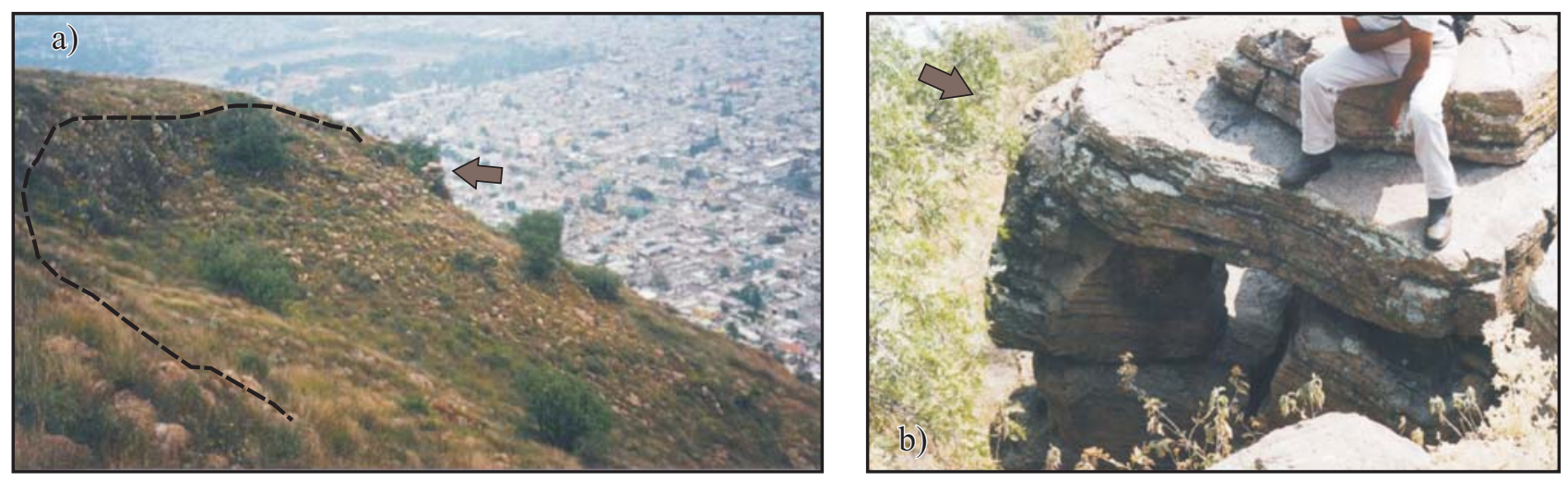

Figura 16. a) Aspecto de la ladera de captación (con línea punteada) donde existen abundantes bloques y detritos, asociados al intenso fracturamiento que afecta a esta zona. La flecha señala un conjunto de bloques (b), los cuales se encuentran apoyados entre sí formando un sistema parecido a columnas y losas. 

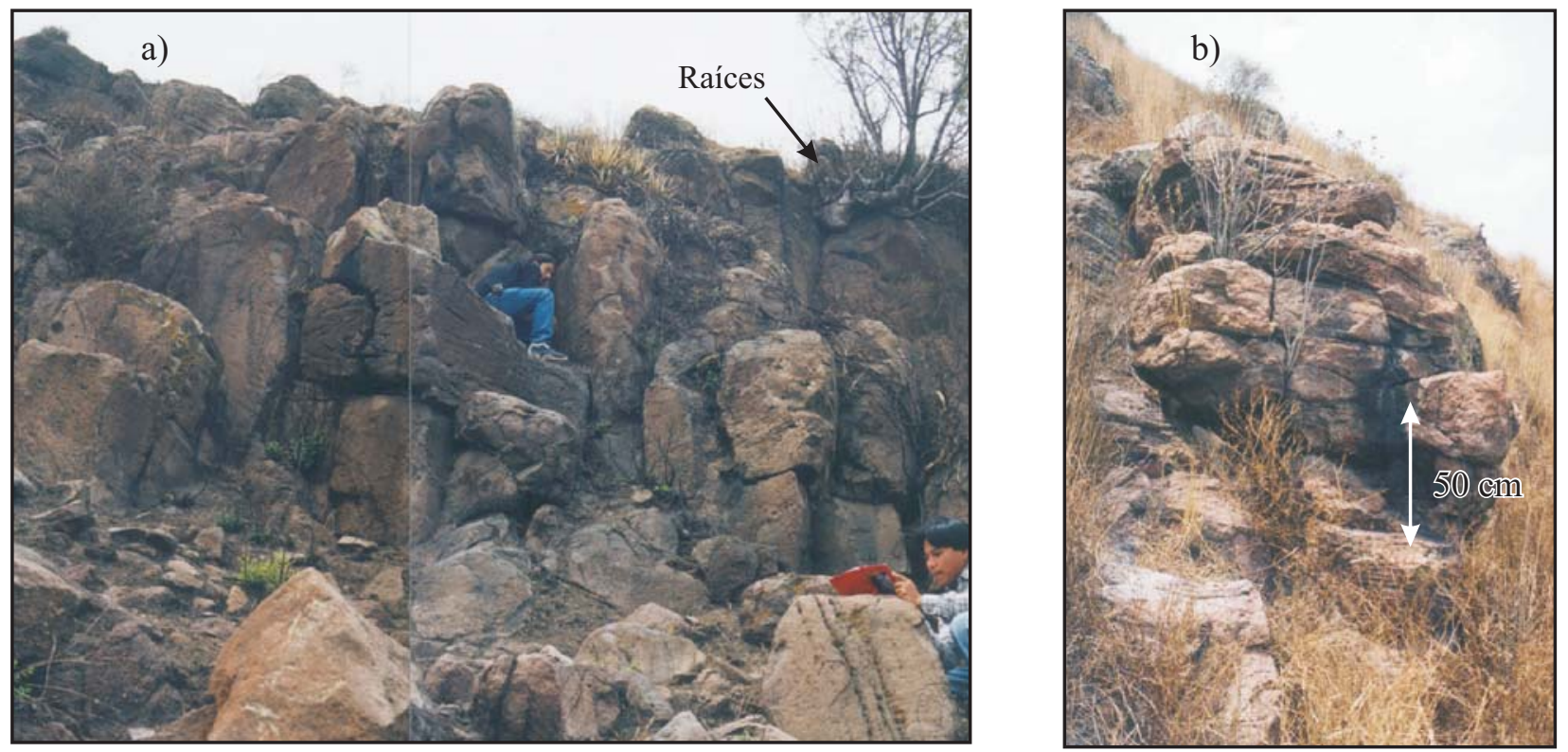

Figura 17. a) Afloramiento donde hay bloques de forma cúbica o subredondeada. Las raíces en muchos casos crecen entre las fracturas siendo un factor importante de disgregación mecánica. b) Bloque fracturado que está apoyado sobre otros de menor tamaño, susceptibles de presentar alguna inestabilidad.

sobre la ladera además de la presencia de todos los tipos de PRM; siguen las zonas I y IV, caracterizados por fuerte pendiente en algunas porciones, presencia de grandes bloques potencialmente inestables y por los cortes verticales de origen antrópico; finalmente la zona III, con pendiente moderada, abundante vegetación y presencia de bloques sueltos sobre la ladera.

\section{Conclusiones y recomendaciones}

El cerro del Tenayo ha sufrido un proceso de urbanización, con efectos negativos en la estabilidad de las laderas, debido a cortes o excavaciones, sobrecarga de las construc- ciones, vibraciones de vehículos pesados, presencia de agua en las fracturas (por fugas o carencia de servicios sanitarios) entre otros. Las condiciones geológicas, morfológicas y estructurales del domo, aunado a la alta vulnerabilidad de muchas viviendas debido a carencias constructivas, implica un importante riesgo para sus habitantes.

Para mitigar el efecto de los PRM en la población e infraestructura civil, es fundamental llevar a cabo estudios a detalle, que tiendan a dar soluciones para cada tipo de movimiento identificado. Esto último es relevante si se tiene en cuenta que la eficacia de un tratamiento geotécnico, depende de la evaluación correcta tanto de las fuerzas resistentes como de las actuantes y del adecuado entendimiento del mecanismo o mecanismos potenciales
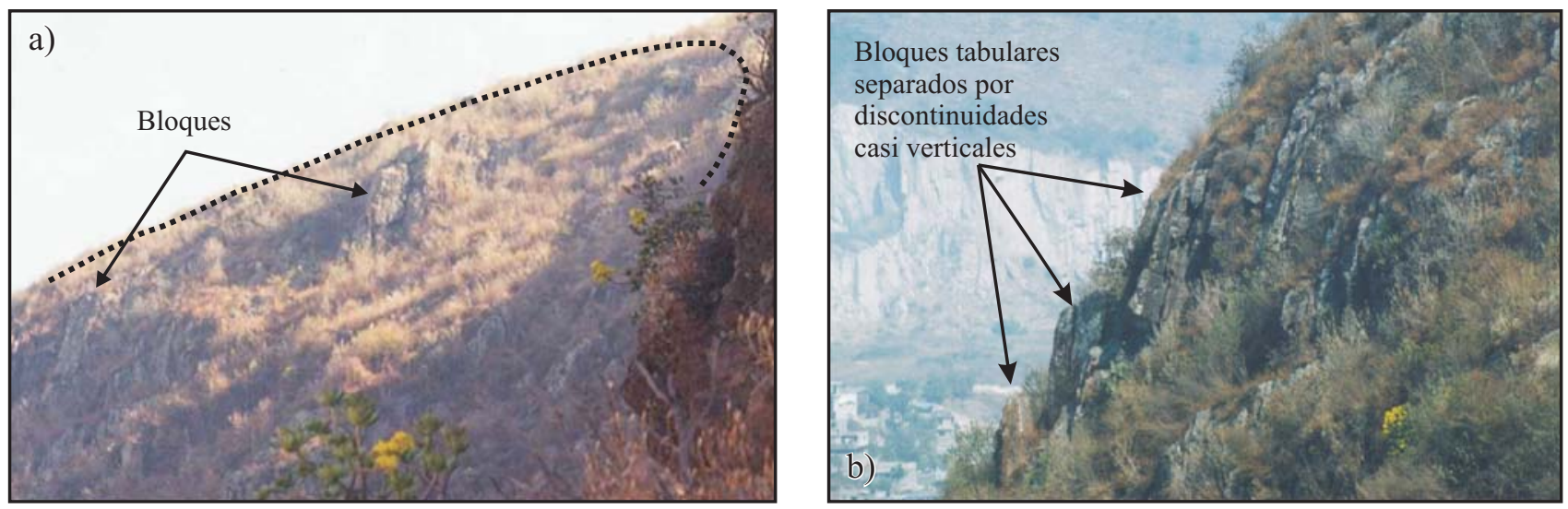

Figura 18. a) Ladera de captación (con línea punteada) donde existen bloques que potencialmente pueden presentar volteo y/o deslizamiento. b) Ejemplo de un frente de bloques que presentan discontunuidades que tienden a la vertical, siendo el volteo el mecanismo potencial de movimiento. 

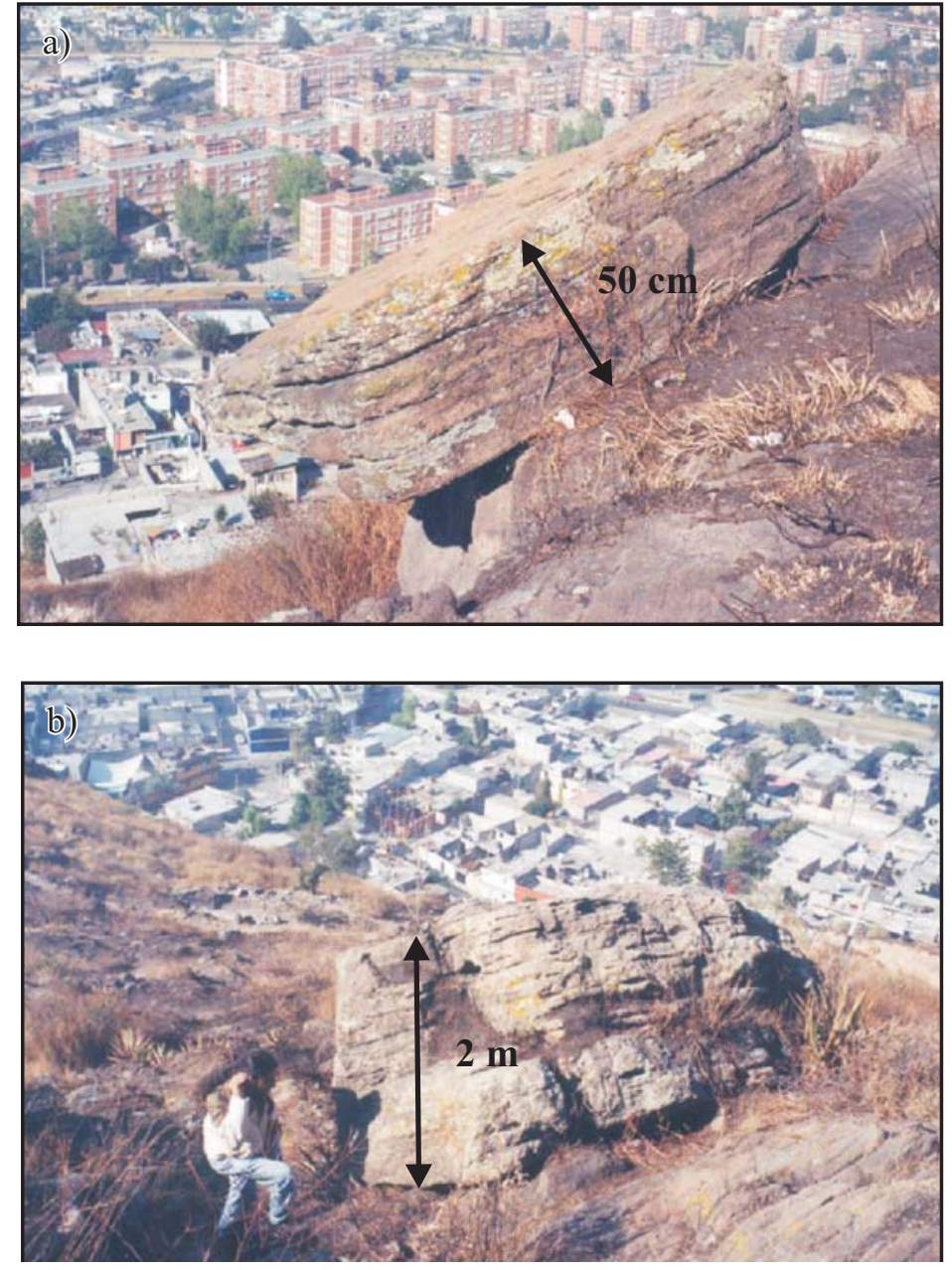

Figura 19. a) Bloque tabular que puede presentar inestabilidad en caso de que se erosione la base o ante empujes sísmicos. b) Este bloque, de $24 \mathrm{~m}^{3}$ aproximadamente, está simplemente apoyado sobre la ladera, con el potencial de rodar hacia la zona de viendas. de movimiento. Es recomendable que en la ejecución de los trabajos de mitigación, se tomen en cuenta las siguientes recomendaciones generales: en caso de realizar la demolición de bloques de roca, ya sea con productos químicos expansores o en forma manual, debe observarse que no se afecte la estabilidad de otros bloques y que el volumen de disgregación pueda ser captado por barreras protectoras. La inyección de mortero o algún otro tipo de cementante en las discontinuidades no es recomendable, debido a que se pueden generar presiones que resulten desfavorables para la estabilidad. Estos trabajos de mitigación son clasificados como de alto riesgo, por lo que el personal deberá estar capacitado y emplear equipo de seguridad. El uso de medidas de drenaje debe considerarse primordial, para evitar la generación de presiones de poro en las discontinuidades; por último, los tratamientos deberán partir de un estudio geotécnico detallado de cada bloque o zona a estabilizar. Los resultados de este trabajo pueden servir para orientar labores de Protección Civil, priorizar los trabajos de mitigación o ser la base para estudios más detallados de peligro o riesgo.

Respecto a las condiciones de riesgo en que se encuentra la población asentada en las laderas del Cerro El Tenayo se recomienda: 1) evitar más construcciones y modificaciones a la ladera original; 2) inhibir la quema de basura; 3) no verter agua de las viviendas de la corona del talud hacia abajo para evitar filtraciones y empujes hidrostáticos; 4) limitar el tránsito de vehículos pesados en los caminos construidos en zonas de ladera; 5) programar un plan de mitigación de riesgo; 6) evaluar el interior de las viviendas para detectar macizos rocosos inestables; 7) informar a los habitantes de la zona para tomar medidas preventivas y evitar inducir algún tipo de inestabilidad por causas antrópicas; 8) realizar estudios geotécnicos detallados para proponer tratamientos de mitigación para cada talud y tipo de movimiento en particular.

\section{Agradecimientos}

Agradecemos la participación de personal del Servicio Geológico Metropolitano en su apoyo en la etapa de campo así como al Lic. Carlos Ruiz. A los ingenieros Daniel Vázquez Leyva, Victoria Flores Moro, Edmundo Polanco 


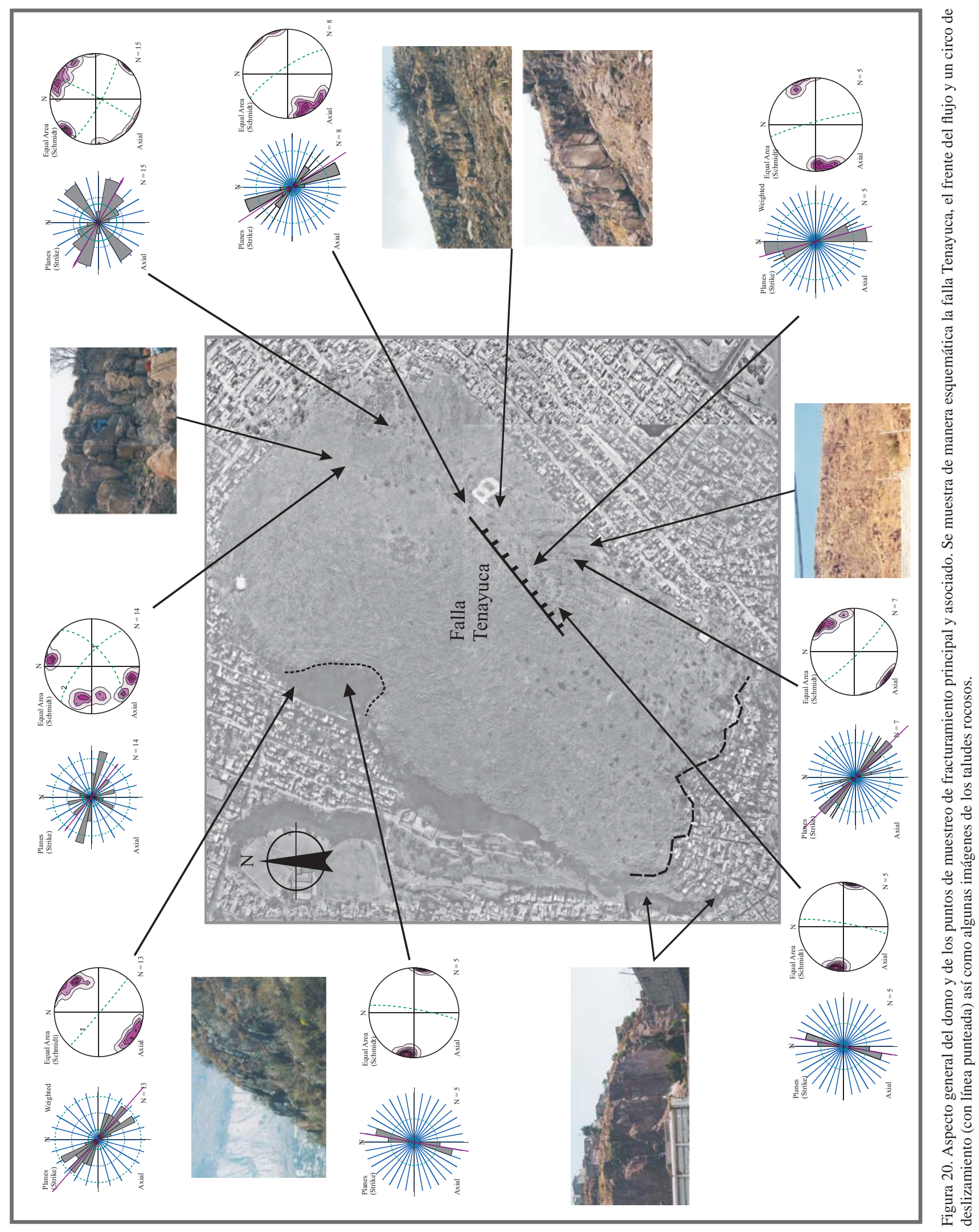


Valenzuela, Adrián Jiménez Haro, Miguel Estrada. Se agradece al Ing. Luis Wintergerst, al Dr. Gustavo Tolson Jones, director del Instituto de Geología y a la Dra. Irasema Alcántara Ayala, directora del Instituto de Geografía por todo su apoyo. Asimismo se agradece a los revisores por sus comentarios y especialmente al Dr. Lugo Hubp.

\section{Referencias bibliográficas}

Campos, M., 2006. Comparación de un método cualitativo con uno bivariado para la evaluación del peligro por procesos de ladera en la sierra de Guadalupe, Edo. de México. Universidad Nacional Autónoma de México, Facultad de Filosofía y Letras, tesis profesional, $86 \mathrm{p}$.

Capra L., Lugo-Hubp, J., Dávila-Hernández, N., 2003. Fenómenos de remoción en masa en el poblado de Zapotitlán de Méndez, Puebla: relación entre litología y tipo de movimiento, Revista Mexicana de Ciencias Geológicas, Vol. 20, num. 2, p. 95-106.

Carlos-Valerio, V., 2003. Estudio de estabilidad de taludes y evaluación del riego geotécnico en el Cerro del Tenayo, Edo. de México. Universidad Nacional Autónoma de México, Facultad de Ingeniería, tesis profesional, $155 \mathrm{p}$.

Concha, A., 2006. Caracterización geomecánica y modelación numérica de los deslizamientos críticos de la Sierra de Guadalupe, Edo. de México. Instituto de Geología, UNAM, 100 p.

De Cserna, Z., De la Fuente, M., Palacios-Nieto, M., Triay, L., MitreSalazar, L., Mota-Palomino, R., 1988. Estructura geológica, gravimetría, sismicidad y relaciones neotectónicas regionales de la Cuenca de México: Universidad Nacional Autónoma de México, Boletín del Instituto de Geología, 104, 71 p.

Espinoza-Hernández, G., 2004. Zonificación de los peligros geológicos en la ladera SW del Cerro del Chiquihuite: Universidad Nacional Autónoma de México, Facultad de Ingeniería, tesis profesional, 79 p.

Fink, J.H. and Anderson, S. W., 2000. Lava domes and coulees. Encyclopedia of volcanoes, Sigurdsson, H., ed. Academic Press, 307-319.

Flores-Moro, G. V., 2006. Geometría estructural y cinemática de la fosa de Barrientos, zona centro-poniente de la Cuenca de México. Instituto Politécnico Nacional, Escuela Superior de Ingeniería y Arquitectura, Ticomán, tesis profesional, $75 \mathrm{p}$

Francis, P. and Oppenheimer, C., 2004. Volcanoes: New York, Oxford University Press, $521 \mathrm{pp}$.

Frausto, M.O., 1999. Derrumbes, deslizamientos y expansión lateral del suelo provocados por sismicidad en el graben de Cuautepec: Región sur de la sierra de Guadalupe, en la ciudad de México. Investigaciones Geográficas, Boletín del Instituto de Geografía, 39, $15-29 \mathrm{p}$.

García-Palomo, A., Carlos-Valerio, V., López-Miguel, C., Galván, A., 2006 a. Los peligros geológicos del Distrito Federal. Revista de Ingeniería Civil, núm 443, p. 4-9.

García-Palomo, A., Carlos-Valerio, V., López-Miguel, C., Galván-García, A., 2006 b. Landslide inventory map of Guadalupe Range, north of the México Basin. Boletín de la Sociedad Geológica Mexicana, Número Especial de Geología Urbana, Tomo LVIII, num. 2, p. 195-204

Gaziev, E., 1984. Estabilidad de los macizos rocosos y métodos de estabilización. Series del Instituto de Ingeniería, No. D-21.

Hoek, E. and Bray, J. W., 1996. Rock Slope Engineering, Institution of Mining and Metallurgy, tercera edición, 358 p.
Hutchinson, J.N.,1988. General Report: Morphological and geotechnical parameters of landslides in relation to geology and hydrogeology, Proceedings of the Fifth International Symposium on Landslides, Vol. I, editado por Christophe Bonnard, p. 3-35.

International Society For Rock Mechanics. Commission On Standardization Of Laboratory And Field Tests, 1978. Suggested Methods for the Quantitative Description of Discontinuities in Rock Masses. Publicado en International Journal of Rock Mechanics and Mining Sciences \& Geomechanics Abstracts., Vol. 15, p. 319-368.

Jacobo-Albarrán, J., 1985. Estudio petrogenético de las rocas de la porción central del Eje Neovolcánico: Instituto Mexicano del Petróleo, Reporte interno.

Lozano-Barraza, L., 1968. Geología de la Sierra de Guadalupe, México, D.F. Instituto Politécnico Nacional, Escuela Superior de Ingeniería y Arquitectura, tesis profesional, $39 \mathrm{p}$.

Lugo-Hubp, J. y Salinas-Montes, A., 1996. Geomorfología de la Sierra de Guadalupe (al norte de la Ciudad de México) y su relación con peligros naturales: Universidad Nacional Autónoma de México, Instituto de Geología, Revista Mexicana de Ciencias Geológicas, v. 13 , num. 2, p. $240-251$.

Margielewski, W., 2006. Structural control and types of movements of rock mass in anisotropic rocks: Case studies in the Polish Flysch Carpathians. Geomorphology 77, p. 47-68.

Mooser, F., 1975. Historia geológica de la Cuenca de México: Memoria de las Obras de Drenaje Profundo del Distrito Federal. México, D.F., Depto. Distrito Federal, t.1 pp. 7-38 y mapa geológico.

Mooser, F., Montiel A., y Zuñiga A., 1992. Nuevo Mapa geológico del surponiente del Valle de México: Simposio Experiencias geotécnicas en la zona poniente del Valle de México. Sociedad Mexicana de Mecánica de Rocas, p. 5-15.

Mooser, F., Montiel A., y Zuñiga A., 1996. Nuevo Mapa Geológico de las Cuencas de México, Toluca y Puebla: Estratigrafía, Tectónica Regional y Aspectos Geotérmicos. Comisión Federal de Electricidad.

Priest, S.D., 1993. Discontinuity analysis for rock engineering. Editorial Chapman \& Hall, Londres, 472 p.

Ramírez, H.J., Hernández, H.F., Rueda, J.G., 1983. Origen, tectónica y cronología volcánica de la Cuenca de México. Boletín de la Asociación de Geólogos Petroleros, Vol. XXXV, num. 2, 37 p.

Servicio Geológico Metropolitano, 2003. Proyecto "Evaluación y zonificación de los peligros geológicos por deslizamiento en las laderas de la Sierra de Guadalupe, Estado de México". Proyecto realizado para el Instituto de Protección Civil del Estado de México.

Tapia-Varela G. y López-Blanco, J., 2001. Mapeo geomorfológico analítico de la porción central de la Cuenca de México: unidades morfogenéticas a escala 1:100 000. Revista Mexicana de Ciencias Geológicas, v.19, num. 1, p. 50-65.

Van der Pluijm, B. A., Stephen M., 2004. Earth structure: and introduction to structural geology and tectonics. Norton \& Company, 2d Edition, $656 \mathrm{p}$.

Vázquez Sánchez, E., Jaimes Palomera R. L., 1990. Geología de la Cuenca de México, en Tópicos Geológicos de la Cuenca de México, editado por la Sociedad Mexicana de Mecánica de Suelos, pp. 1- 24.

Wheeler, R. L. and Dixon, J. M., 1980. Intensity of systematic joints: methods and aplication. Geology, v. 8, p 230-233.

Manuscrito recibido: Febrero 6, 2008

Manuscrito corregido recibido: Junio 15, 2008

Manuscrito aceptado: Junio 25, 2008 